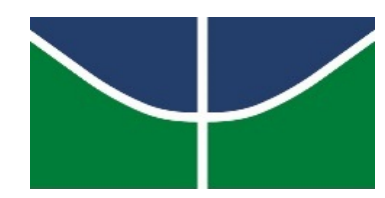

Universidade de Brasília

Instituto de Ciências Humanas

Departamento de Geografia

Programa de Pós-Graduação em Geografia

\title{
AVALIAÇÃO DA ACURÁCIA VERTICAL DO MODELO SRTM PARA O BRASIL
}

ALEX GOIS ORLANDI

Dissertação de Mestrado

Brasília - Distrito Federal

Dezembro/2016 


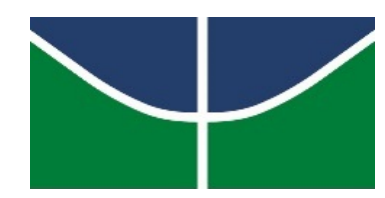

Universidade de Brasília

Instituto de Ciências Humanas

Departamento de Geografia

Programa de Pós-Graduação em Geografia

\title{
AVALIAÇÃO DA ACURÁCIA VERTICAL DO MODELO SRTM PARA O BRASIL
}

\author{
ALEX GOIS ORLANDI \\ Orientador: Renato Fontes Guimarães \\ Co-orientador: Osmar Abílio de Carvalho Junior
}

Dissertação de Metrado

\author{
Brasília - Distrito Federal \\ Dezembro/2016
}


Universidade de Brasília

Instituto de Ciências Humanas

Departamento de Geografia

Programa de Pós-Graduação em Geografia

\title{
AVALIAÇÃO DA ACURÁCIA VERTICAL DO MODELO SRTM PARA O BRASIL
}

\begin{abstract}
Alex Gois Orlandi
Dissertação apresentada ao Programa de Pós-Graduação em Geografia-Gestão Territorial e Ambiental, Instituto de Ciências Humanas da Universidade de Brasília, como requisito parcial para a obtenção do título de Mestre em Geografia na área de Geoprocessamento.
\end{abstract}

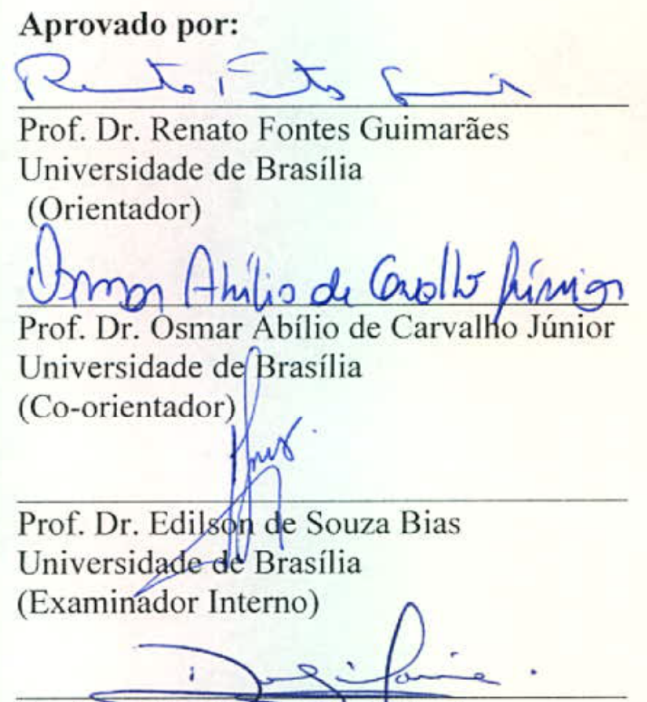

Prof. Dr. Douglas Corbari Corrêa

Diretoria de Serviço Geográfico-DSG

(Examinador Externo)

Brasília, DF, 16 de dezembro de 2016. 
FICHA CATALOGRÁFICA

ORLANDI, ALEX GOIS

Avaliação da acurácia vertical do modelo SRTM para o Brasil. 2016. 54p.

(GEA/IH/UnB, Mestre, Geografia - Geoprocessamento, 2016).

Dissertação de Mestrado - Universidade de Brasília. Instituto de Ciências Humanas.

Departamento de Geografia.

1. Missão SRTM

2. Acurácia Vertical

4. Modelo Digital de Elevação

3. Interferometria

É concedida à Universidade de Brasília permissão para reproduzir cópias desta Dissertação e emprestar ou vender tais cópias somente para propósitos acadêmicos e científicos. O autor reserva outros direitos de publicação e nenhuma parte desta dissertação de mestrado pode ser reproduzida sem a autorização por escrito do autor.

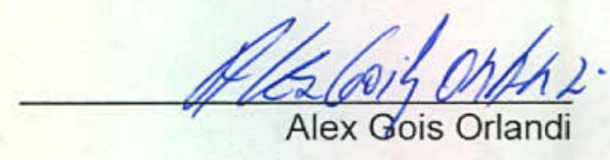




\section{Dedicatória}

Dedico este trabalho primeiramente a Jesus Cristo, autor e consumador da minha fé, que me ensina cotidianamente o quanto preciso me transformar para me tornar um homem melhor e mais digno do seu amor.

Certamente após Ele, só poderia vir minha amada esposa Loana, sem a qual o tempo investido nesses estudos não renderiam tanto e sem a motivação que me diz a todo instante que sou capaz de fazer muito mais e melhor! Lu, eu te amo para sempre, minha Linda!!

Ao meu filho Álex Baruc, que com seus 5 aninhos (a serem completados no Natal) teve minhas ausências justificadas pela dedicação a esses resultados, mas nunca deixou de estar na minha mente e no meu coração: filho, papai te ama e se esforça para ser para você o melhor exemplo que eu puder!!

Aos meus irmãos, Alexandre e Aline, por serem meus guardiões desde a infância e me incentivarem desde muito cedo, acreditando em meu potencial.

À minha amada mãe que me ensinou tantas coisas, mas principalmente o significado de amor, cuidado e doação. Quanto mais o tempo passa, mais vejo o quanto aprendi com ela! Mãe, te amo!!

Ao meu pai, que me deu a vida e que se orgulha das minhas conquistas e da minha trajetória. Obrigado pai!! 


\section{Agradecimentos}

Este é um momento muito especial no qual não poderia deixar de agradecer a algumas pessoas que se fizeram presentes nos momentos mais significativos durante a realização desta pesquisa.

Gostaria de agradecer à Agência Nacional de Energia Elétrica (ANEEL) por possibilitar o desenvolvimento deste estudo colaborando não só com os dados, mas também com todo o incentivo para a conclusão deste trabalho, particularmente à Superintendência de Gestão Técnica da Informação (SGI) e à equipe de Geoprocessamento da Agência.

Externo também meus agradecimentos ao ex-Chefe Odenir José dos Reis que me ensinou, sobre tudo, a pensar melhor e a questionar o motivo das atitudes e revisitar os fundamentos de uma decisão: "por que estou fazendo isso mesmo?".

Obrigado ao Prof. Renato pelas correções e orientações sempre enriquecedoras e ao Prof. Osmar pelas ideias que melhoraram bastante a qualidade final e valorizaram os resultados encontrados.

Não poderia deixar de agradecer ao Prof. Edilson, não somente pelas matérias cursadas com ele, mas também pela convivência e contribuições extremamente significativas desde a etapa de qualificação.

Meus sinceros agradecimentos ao Tenente-Coronel Corbari, chefe do CIGEX, pela prontidão em contribuir de forma tão significativa para o aperfeiçoamento do trabalho. 
Eu te amo, ó Senhor, minha força. O Senhor é a minha rocha, a minha fortaleza e o meu libertador; o meu Deus é o meu rochedo"

(SALMO 18:1-2) 


\section{RESUMO}

Esse trabalho tem como objetivo determinar a acurácia vertical do Modelo Digital de Elevação (MDE) interferométrico obtido a partir das várias versões provenientes do Shuttle Radar Topographic Mission (SRTM) em todo o Brasil, comparando-os com 1.087 pontos medidos diretamente em campo, obtidos com rastreadores Global Navigation satellite System (GNSS) ou métodos de topografia. Esses pontos foram utilizados para o apoio básico às restituições aerofotogramétricas utilizadas nos estudos de inventários hidrelétricos ou projetos básicos de usinas hidrelétricas em território brasileiro. Neste trabalho, são comparados os seguintes MDEs: a) modelo disponibilizado pela EMBRAPA, b) modelo Hydrological data and maps based on Shuttle Elevation Derivatives at multiple Scales (HydroSHEDS), fornecido pelo United States Geological Survey (USGS) c) Consultative Group for International Agricultural ResearchConsortium for Spatial Information (CGIAR_CSI), e d) Jhonatan Ferranti. Neste estudo, o Brasil foi divido em faixas com $4^{\circ}$ de latitude, visando à distribuição mais homogênea possível dos dados de campo e minimizando a possibilidade de ocorrência de grandes áreas sem medições. Os resultados demonstraram que a acurácia vertical do Modelo fornecido pelo SRTM varia ao longo do território brasileiro, apresentando para os 1.087 pontos distribuídos no Brasil: erro médio de 8,96m e desvio-padrão de 11,20m para os modelos da EMBRAPA; erro médio de $0,24 \mathrm{~m}$ e desvio-padrão de $12,70 \mathrm{~m}$ para o HydroSHEDS; erro médio de 9,78m e desvio-padrão de 8,16m para CGIAR-CSI; erro médio de 6,33m e desvio-padrão de 7,22m para Jhonatan Ferranti. Além disso, no conjunto dos 1.087 pontos, todos os Modelos podem ser classificados no Padrão de Exatidão Cartográfica como "A" para a escala de 1:100.000, mas podem apresentar resultados melhores em termos locais. Também foram evidenciadas as influências direta da declividade e da vegetação na acurácia altimétrica dos pontos. Tais conclusões reforçam a ideia de que o usuário deve ter a exata noção da acurácia esperada do Modelo e que sua acurácia altimétrica também varia em razão da fonte em que o modelo é obtido, apesar de possuir a mesma resolução espacial. Assim, tais fatores são importantes, mas não diminuem o valor agregado por esse Modelo gratuito para muitos estudos que sejam compatíveis com a escala indicada para sua utilização.

Palavras-chave: missão SRTM, acurácia vertical, interferometria, modelo digital de elevação. 


\begin{abstract}
This work aims at determine the vertical accuracy of the Interferometric Digital Elevation Model (DEM) obtained from the various versions of the Shuttle Radar Topographic Mission (SRTM) throughout Brazil, comparing them with 1,087 points measured directly in the field, which were obtained With Global Navigation Satellite System (GNSS) trackers or topography methods. These points were used for the basic support to aerophotogrammetric restitutions used in the studies of hydroelectric inventories or basic projects of hydroelectric plants in Brazilian territory. In this work, the following DEMs are compared: a) model provided by EMBRAPA, b) Hydrological data model and maps based on Shuttle Elevation Derivatives at multiple Scales (HydroSHEDS), provided by the United States Geological Survey (USGS) c) Consultative Group for International Agricultural Research-Consortium for Spatial Information (CGIAR_CSI), and d) Jhonatan Ferranti. In this study, Brazil was divided into $4^{\circ}$ latitude bands, aiming at the most homogeneous distribution of field data and minimizing the possibility of large areas without measurements. The results showed that the vertical accuracy of the Model provided by the SRTM varies throughout the Brazilian territory, presenting for the 1,087 points distributed in Brazil: Mean error of $8.96 \mathrm{~m}$ and standard deviation of $11.20 \mathrm{~m}$ for EMBRAPA models; Mean error of $0.24 \mathrm{~m}$ and standard deviation of $12.70 \mathrm{~m}$ for the HydroSHEDS; Mean error of $9.78 \mathrm{~m}$ and standard deviation of $8.16 \mathrm{~m}$ for CGIAR-CSI; Mean error of $6.33 \mathrm{~m}$ and standard deviation of $7.22 \mathrm{~m}$ for Jhonatan Ferranti. In addition, for all 1,087 points, all Models can be classified as Cartographic Accuracy Standard as "A" for the 1: 100,000 scale but may present better results locally. The direct influences of slope and vegetation on the altimetric accuracy of the points were also evidenced. These conclusions reinforce the idea that the user must have the exact notion of the expected accuracy of the Model and that its altimetric accuracy also varies due to the source in which the model is obtained, despite having the same spatial resolution. Thus, these factors are important but do not diminish the value added by this free model for many studies that are compatible with the scale indicated for their use.
\end{abstract}

Keywords: SRTM mission, vertical accuracy, interferometry, digital elevation model. 
SUMÁRIO

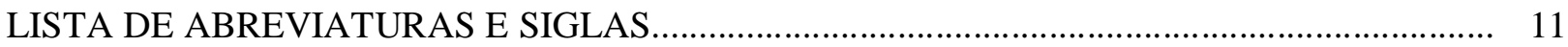

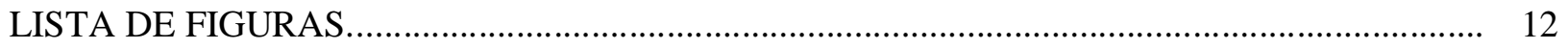

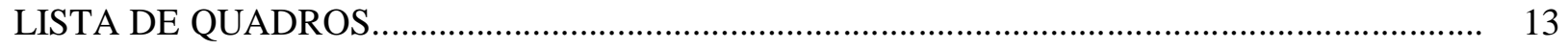

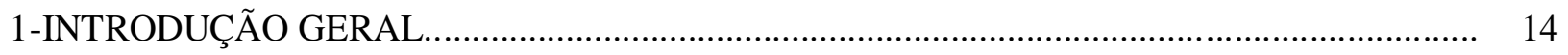

2-DESENVOLVIMENTO-ARTIGO_................................................................................. 20

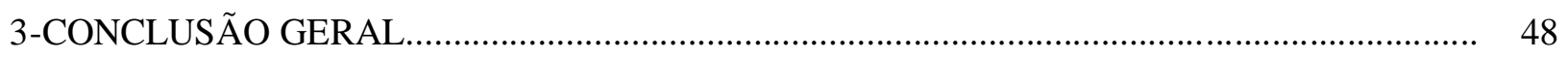

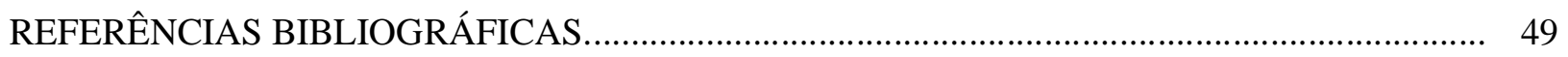




\section{LISTA DE ABREVIATURAS E SIGLAS}

$\begin{array}{ll}\text { ANEEL } & \text { Agência Nacional de Energia Elétrica } \\ \text { CEDOC } & \text { Centro de Documentação da Agência Nacional de Energia Elétrica } \\ \text { CONCAR } & \text { Comissão Nacional de Cartografia } \\ \text { CGIAR-CSI } & \begin{array}{l}\text { Consultative Group for International Agricultural Research- } \\ \text { Consortium for Spatial Information }\end{array} \\ \text { DSG } & \text { Diretoria de Serviço Geográfico } \\ \text { EMBRAPA } & \text { Empresa Brasileira de Pesquisa Agropecuária } \\ \text { GNSS } & \text { Global Navigation Satellite System } \\ \text { HYDROSHEDS } & \begin{array}{l}\text { Hydrological data and maps based on Shuttle Elevation Derivatives at } \\ \text { multiple Scales }\end{array} \\ \text { MDE } & \text { Modelo Digital de Elevação } \\ \text { MDT } & \text { Modelo Digital de Terreno } \\ \text { PEC } & \text { Padrão de Exatidão Cartográfica } \\ \text { PEC-PCD } & \text { Padrão de Exatidão Cartográfica para Produtos Cartográficos Digitais } \\ \text { RMSE } & \text { Root Mean Square Error } \\ \text { TIN } & \text { Triangulated Irregular Network }\end{array}$




\section{LISTA DE FIGURAS}

FIGURA I-INTRODUÇÃO GERAL: Localização dos pontos entre as Latitudes $06^{\circ} \mathrm{N}$ e $10^{\circ} \mathrm{S} \ldots \ldots \ldots \ldots \ldots . . . . . . .16$

FIGURA II-INTRODUÇÃO GERAL. Localização dos pontos entre as Latitudes $14^{\circ} \mathrm{N}$ e $30^{\circ} \mathrm{S} . . . \ldots \ldots \ldots \ldots . . . . . .17$

FIGURA 1-DESENVOLVIMENTO: Pontos de estudo sobre a acurácia do Modelo SRTM no Mundo.

FIGURA 2-DESENVOLVIMENTO: Brasil dividido em faixas com 4 graus de latitude.

FIGURA 3-DESENVOLVIMENTO: Ponto medido com receptor Geodésico em Abunã-RO, Brasil......

FIGURA 4-DESENVOL VIMENTO: Exemplo de Pontos do inventário do rio das Caveiras coletados no CEDOC da ANEEL abrangendo a região entre os paralelos $30^{\circ} \mathrm{S}$ e $26^{\circ} \mathrm{S}$.

FIGURA 5-DESENVOLVIMENTO: Exemplo de Pontos do inventário do rio Sargento sobreposto ao TIN obtido por meio do SRTM na região entre os paralelos $30^{\circ} \mathrm{S}$ e $26^{\circ} \mathrm{S}$

FIGURA 6-DESENVOLVIMENTO: Gráfico do Erro Médio em Função da Declividade (\%)

FIGURA 7-DESENVOLVIMENTO: Gráfico do Desvio-Padrão dos Erros em Função da Declividade $(\%)$

FIGURA 8-DESENVOLVIMENTO: Gráfico do Erro Médio em Função da Declividade, excluídos os 100 Maiores Erros.

FIGURA 9-DESENVOLVIMENTO: Análise dos Maiores Erros por Faixa de Latitude e sua incidência em Regiões com Vegetação. 


\section{LISTA DE QUADROS}

QUADRO 1- Resumo de estudos que determinam os erros de acurácia de dados SRTM localizados na Figura 1 .....

QUADRO 2-: Resumo das acurácias Obtidas por Faixa de Latitude

QUADRO 3-: Valores do PEC para as Classes A, B e C nas escalas 1:100.000 e 1:50.000.

QUADRO 4-: Valores do PEC-PCD para as Classes A, B e C nas escalas 1:100.000 e 1:50.000.....

QUADRO 5- Resumo das Acurácias Obtidas por Faixa de Latitude.

QUADRO 6- Resumo das Acurácias Obtidas por Faixa de Latitude

QUADRO 7- Classificação quanto ao PEC por Faixa de Latitude

QUADRO 8- Classificação quanto ao PEC-PCD por Faixa de Latitude.

QUADRO 9- Resultados de estudos globais e deste estudo. 


\section{INTRODUÇÃO GERAL}

Um dos grandes produtos da fotogrametria ou do sensoriamento remoto que lhe seja tecnicamente similar é a possibilidade de gerar modelos digitais de elevação (COELHO FILHO \& BRITO, 2007), sendo esse modelo a ferramenta para muitas finalidades, desde parâmetros topográficos dos inventários de geleiras (FREY \& PAUL, 2012) até cálculo de áreas de inundação (SUWANDANA et al 2012).

Ainda há um fator que tem impulsionado de forma significativa os estudos subsidiados por modelos digitais de elevação: a disponibilização de modelos globais de forma gratuita. Nesse contexto, citam-se o Global 30 e o Shuttle Radar Topographic Mission (SRTM) (AZIZIAN \& SHOKOOHI, 2015), sendo este último mais preciso e objeto de estudo em muitos artigos (NÓBREGA et al., 2005, GROHMANN et al., 2008, MANTELLI et al., 2009, MEDEIROS et al., 2009, MICELI et al., 2011 e FREY \& PAUL, 2012).

Além disso, é relevante salientar que o Modelo SRTM é reprocessado por instituições ou pessoas, a fim de que suas falhas sejam corrigidas e seu desempenho seja melhorado (MIRANDA, 2005; MOURA et al, 2014; USGS, 2015; CGIAR-CSI, 2016; FERRANTI, 2015).

Interessante observar que as avaliações do SRTM, normalmente, concentramse em 3 fatores: a) avaliação da acurácia vertical do SRTM (BERRY et al, 2007; MICELI et al, 2011; ROBINSON et al, 2014); b) a relação entre a declividade do terreno e os erros altimétricos (GOROKHOVICH \& VOUSTIANIOUK, 2006; MOURATIDIS, A. et al., 2010; SHORTRIDGE \& MESSINA, 2011); c) a influência da vegetação na acurácia altimétrica do Modelo (LIU, 2008; SHORTRIDGE \& MESSINA, 2011). 
Dessa forma, este trabalho tem como objetivo determinar a acurácia vertical do Modelo Digital de Elevação (MDE) interferométrico obtido a partir das várias versões provenientes do Shuttle Radar Topographic Mission (SRTM) em todo o Brasil, comparando-os com 1.087 pontos medidos diretamente em campo obtidos com rastreadores Global Navigation Satellite System (GNSS) ou métodos de topografia, avaliando sua acurácia e analisando se existe influência entre essa acurácia e os fatores declividade e vegetação. Esses pontos foram utilizados nos estudos de inventários hidrelétricos ou projetos básicos de usinas hidrelétricas em território brasileiro aprovados pela Agência Nacional de Energia Elétrica. A Agência estabelece em suas Diretrizes de Cartografia a forma de Obtenção desses pontos para que os estudos sejam por ela aprovados (ANEEL, 2009).

Neste ponto, cabe ressaltar que no Modelo Digital de Elevação fornecido pelo SRTM a onda utilizada para gerar o Modelo Digital de Elevação é espalhada pela copa da vegetação, fazendo com que o modelo represente a superfície do topo das árvores e não o terreno em si (BROCHADO, 2015), como se fosse Modelo Digital de Superfície (MDS). Essa distinção é bastante relevante, pois, neste estudo, avalia-se o SRTM como um Modelo Digital de Terreno (MDT), uma vez que os pontos que servem de subsídio foram medidos diretamente no terreno, representando sua superfície real (CAMARGOS et al., 2015). Assim, podemos resumir que o Modelo Digital Elevação (MDE) seria um gênero e MDT e MDS, suas espécies.

A área de estudo é todo o território brasileiro. Os pontos estão divididos em todas as regiões do país, de Norte a Sul, estando em nove regiões topograficamente movimentadas, conforme mapas abaixo (Figura I e II). 

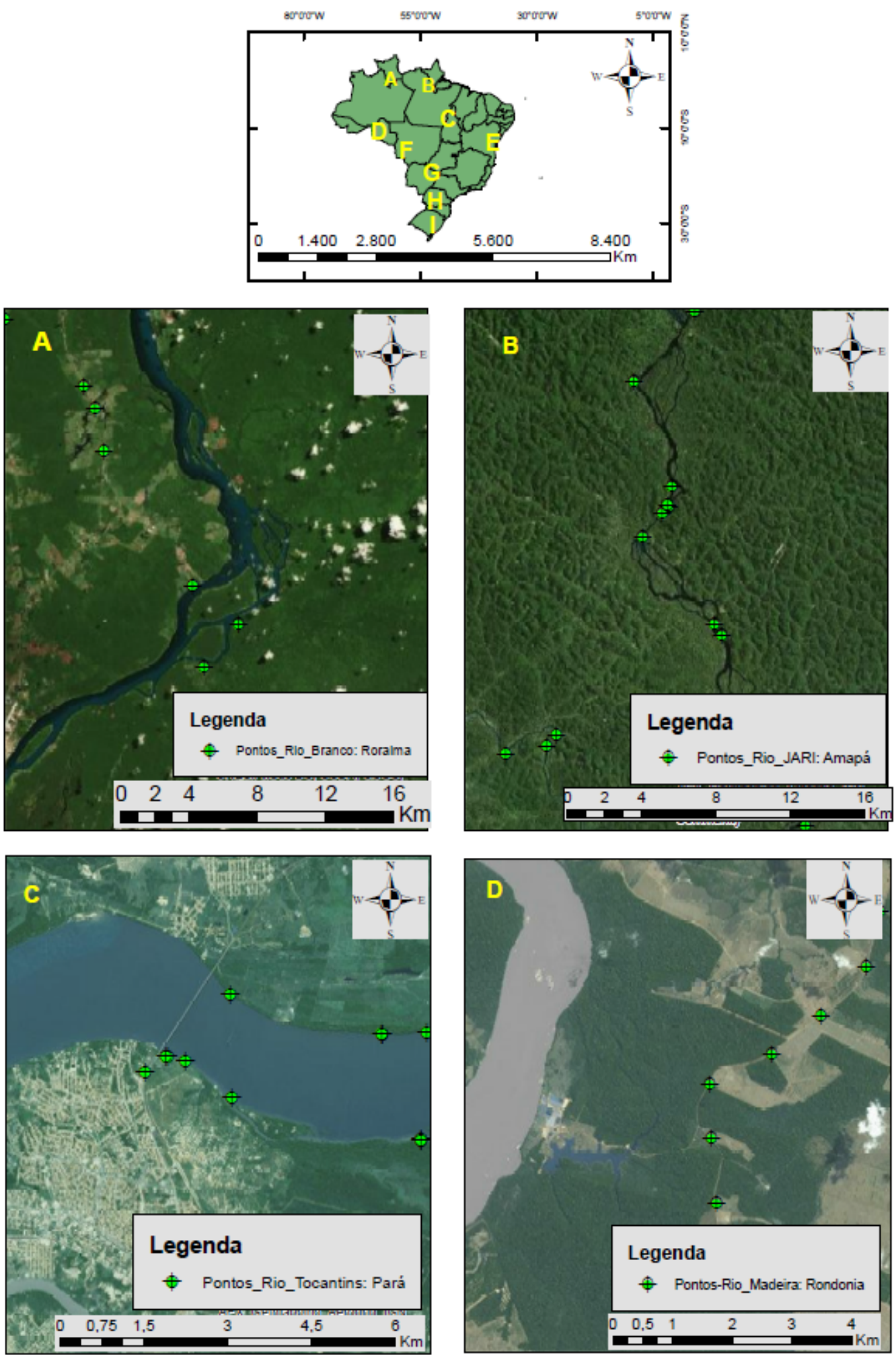

Figura I- Localização dos pontos entre as Latitudes $06^{\circ} \mathrm{N}$ e $10^{\circ} \mathrm{S}$.

Fonte das Imagens: Esri, DigitalGlobe, GeoEye, Earthstar Geographicas, CNES/Airbus DS, USDA, USGS, AEX, Getmapping, Aerogrid, IGN, IGP, swisstopo, the GISUser Community. 

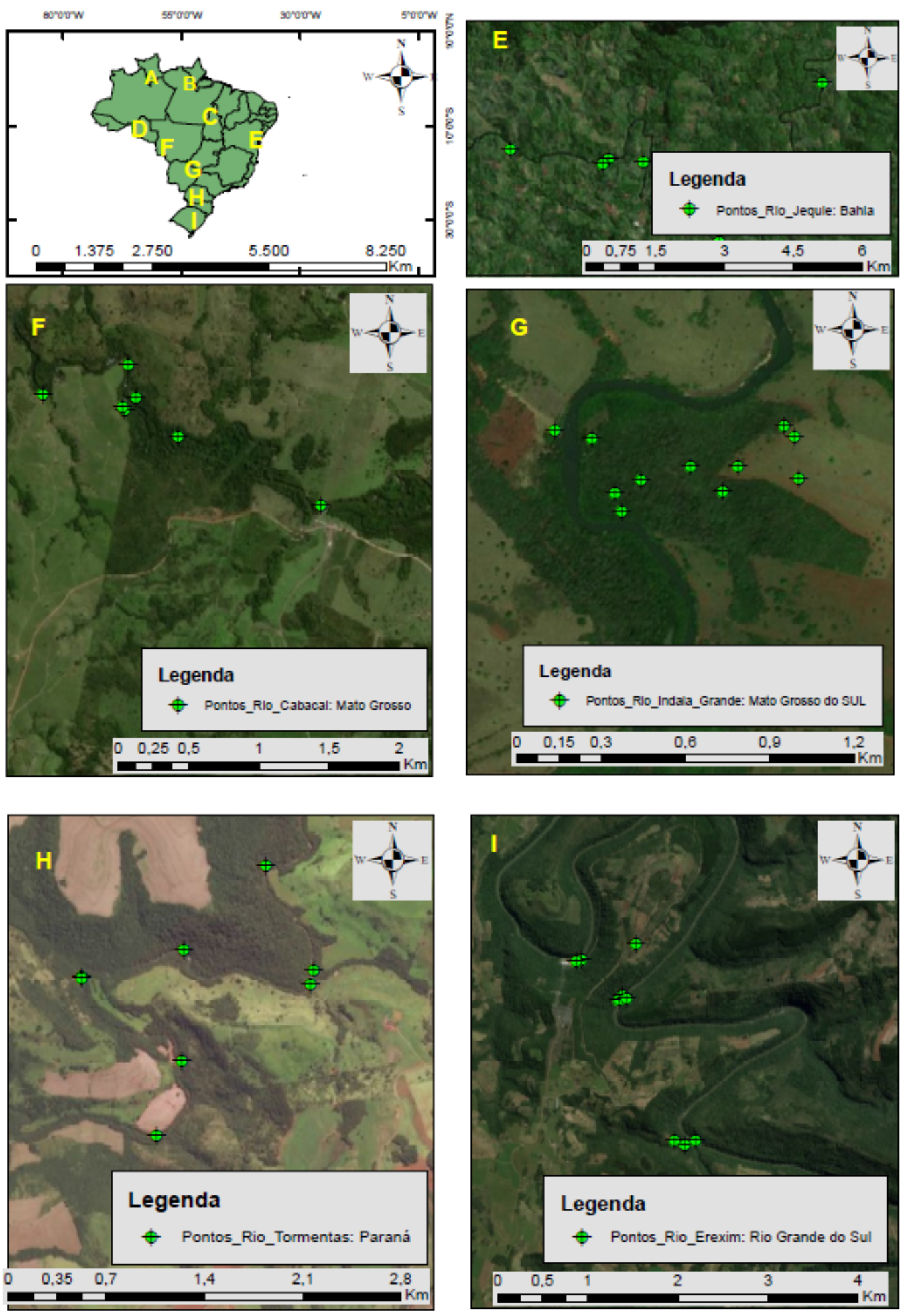

Figura II- Localização dos pontos entre as Latitudes $14^{\circ} \mathrm{S}$ e $30^{\circ} \mathrm{S}$.

Fonte das Imagens: Esri, DigitalGlobe, GeoEye, Earthstar Geographicas, CNES/Airbus DS, USDA, USGS, AEX, Getmapping, Aerogrid, IGN, IGP, swisstopo, the GISUser Community. 
Segundo o Ministério do Meio Ambiente (MMA), o Brasil está dividido em 6 biomas: Amazônico, Caatinga, Mata Atlântica, Cerrado, Pantanal e Pampa (MMA, 2016). Este estudo não contempla os biomas Caatinga e Pantanal em função das grandes dimensões do Brasil, não sendo possível no escopo deste estudo a cobertura desses biomas.

As regiões identificadas pelas letras "A", "B", “C", "D" e "F" (Figura 1 e Figura 2) estão localizadas no bioma amazônico que possui área aproximada de 6,5 milhões de quilômetros quadrados. Esse bioma possui as seguintes características: vegetação dominante por florestas ombrófila densa e floresta ombrófila aberta e árvores altas (SFB, 2016; Portal Brasil, 2016); e planícies periodicamente inundadas.

As regiões identificadas pelas letras "E" e "H" (Figura 2) estão localizadas no bioma Mata-Atlântica. Esse bioma possui as seguintes características: vegetação dominante por florestas ombrófila densa e árvores altas (SFB, 2106; Portal Brasil, 2016); e engloba cadeias de montanhas, vales, planaltos e planícies (Portal Brasil, 2016);

A região identificada pela letra "G” (Figura 2) está localizada no bioma Cerrado. Esse bioma possui as seguintes características: vegetação dominante por florestas de galeria, matas ciliares e ribeirinhas com folhagem persistente durante todo o ano (SFB, 2106; Portal Brasil, 2016); e planaltos com extensas chapadas.

A região identificada pela letra "I" (Figura 2) está localizada no bioma Pampa. Esse bioma, que está localizado no Rio Grande do Sul, possui as seguintes características: vegetação dominada por arbustos e florestas ombrófila densa (árvores altas) e estacional decidual, mas as florestas são pouco comuns (SFB, 2106; Portal Brasil, 2016); e relevo levemente ondulado. 
Como citado, os pontos utilizados nesse estudo foram obtidos, em sua maioria, em estudos de inventário hidrelétricos aprovados pela Agência Nacional de Energia Elétrica, ANEEL, (BRASIL, 2016). Por isso, sempre estarão próximos a rios e até em suas margens, sendo comum a existência de vegetação nas margens dos rios. Esse fato contribuirá para que seja feita a análise da influência da vegetação na acurácia do SRTM.

Pelo exposto, considera-se que a contribuição deste trabalho pode expandir o conhecimento do Modelo SRTM no Brasil e também indicar qual seria, dentre os Modelos de elevação aqui analisados, aquele mais confiável para trabalhos em território brasileiro. 


\title{
2. DESENVOLVIMENTO
}

\section{AVALIAÇÃO DA ACURÁCIA VERTICAL DO MODELO SRTM PARA O BRASIL}

\author{
Assessment of vertical accuracy of the SRTM model for Brazil \\ Alex Gois Orlandi ${ }^{1}$ \\ Renato Fontes Guimarães ${ }^{2}$ \\ Osmar Abílio de Carvalho Junior ${ }^{3}$ \\ 1 Agência Nacional de Energia Elétrica (ANEEL) \\ SGAN 603 módulo J - 70830-110 - Brasília-DF, Brasil \\ alexorlandi@aneel.gov.br \\ ${ }^{2,3}$ Universidade de Brasília-Unb \\ Campus Universitário Darcy Ribeiro-70910-900 - Brasília - DF, Brasil \\ renatofg@unb.br
}

RESUMO

\begin{abstract}
Esse trabalho tem como objetivo determinar a acurácia vertical do Modelo Digital de Elevação (MDE) interferométrico obtido a partir das várias versões provenientes do Shuttle Radar Topographic Mission (SRTM) em todo o Brasil, comparando-os com 1.087 pontos medidos diretamente em campo, obtidos com rastreadores Global Navigation satellite System (GNSS) ou métodos de topografia. Esses pontos foram utilizados para o apoio básico às restituições aerofotogramétricas utilizadas nos estudos de inventários hidrelétricos ou projetos básicos de usinas hidrelétricas em território brasileiro. Neste trabalho, são comparados os seguintes MDEs: a) modelo disponibilizado pela EMBRAPA, b) modelo Hydrological data and maps based on Shuttle Elevation Derivatives at multiple Scales (HydroSHEDS), fornecido pelo United States Geological Survey (USGS) c) Consultative Group for International Agricultural ResearchConsortium for Spatial Information (CGIAR_CSI), e d) Jhonatan Ferranti. Neste estudo, o Brasil foi divido em faixas com $4^{\circ}$ de latitude, visando à distribuição mais homogênea possível dos dados de campo e minimizando a possibilidade de ocorrência de grandes áreas sem medições. Os resultados demonstraram que a acurácia vertical do Modelo fornecido pelo SRTM varia ao longo do território brasileiro, apresentando para os 1.087 pontos distribuídos no Brasil: erro médio de $8,96 \mathrm{~m}$ e desvio-padrão de $11,20 \mathrm{~m}$ para os modelos da EMBRAPA; erro médio de 0,24m e desvio-padrão de 12,70m para o HydroSHEDS; erro médio de 9,78m e desvio-padrão de 8,16m para CGIAR-CSI; erro médio de 6,33m e desvio-padrão de 7,22m para Jhonatan Ferranti. Além disso, no conjunto dos 1.087 pontos, todos os Modelos podem ser classificados no Padrão de Exatidão Cartográfica como "A" para a escala de 1:100.000, mas podem apresentar resultados melhores em termos locais. Também foram evidenciadas as influências direta da declividade e da vegetação na acurácia altimétrica dos pontos. Tais conclusões reforçam a ideia de que o usuário deve ter a exata noção da acurácia esperada do Modelo e que sua acurácia altimétrica também varia em razão da fonte em que o modelo é obtido, apesar de possuir a mesma resolução espacial. Assim, tais fatores são importantes, mas não diminuem o valor agregado por esse Modelo gratuito para muitos estudos que sejam compatíveis com a escala indicada para sua utilização.
\end{abstract}

Palavras-chave: missão SRTM, acurácia vertical, interferometria, modelo digital de elevação. 


\begin{abstract}
This work aims at determine the vertical accuracy of the Interferometric Digital Elevation Model (DEM) obtained from the various versions of the Shuttle Radar Topographic Mission (SRTM) throughout Brazil, comparing them with 1,087 points measured directly in the field, which were obtained With Global Navigation Satellite System (GNSS) trackers or topography methods. These points were used for the basic support to aerophotogrammetric restitutions used in the studies of hydroelectric inventories or basic projects of hydroelectric plants in Brazilian territory. In this work, the following DEMs are compared: a) model provided by EMBRAPA, b) Hydrological data model and maps based on Shuttle Elevation Derivatives at multiple Scales (HydroSHEDS), provided by the United States Geological Survey (USGS) c) Consultative Group for International Agricultural Research-Consortium for Spatial Information (CGIAR_CSI), and d) Jhonatan Ferranti. In this study, Brazil was divided into $4^{\circ}$ latitude bands, aiming at the most homogeneous distribution of field data and minimizing the possibility of large areas without measurements. The results showed that the vertical accuracy of the Model provided by the SRTM varies throughout the Brazilian territory, presenting for the 1,087 points distributed in Brazil: Mean error of $8.96 \mathrm{~m}$ and standard deviation of $11.20 \mathrm{~m}$ for EMBRAPA models; Mean error of $0.24 \mathrm{~m}$ and standard deviation of $12.70 \mathrm{~m}$ for the HydroSHEDS; Mean error of $9.78 \mathrm{~m}$ and standard deviation of $8.16 \mathrm{~m}$ for CGIAR-CSI; Mean error of $6.33 \mathrm{~m}$ and standard deviation of $7.22 \mathrm{~m}$ for Jhonatan Ferranti. In addition, for all 1,087 points, all Models can be classified as Cartographic Accuracy Standard as "A" for the 1: 100,000 scale but may present better results locally. The direct influences of slope and vegetation on the altimetric accuracy of the points were also evidenced. These conclusions reinforce the idea that the user must have the exact notion of the expected accuracy of the Model and that its altimetric accuracy also varies due to the source in which the model is obtained, despite having the same spatial resolution. Thus, these factors are important but do not diminish the value added by this free model for many studies that are compatible with the scale indicated for their use.
\end{abstract}

Keywords: SRTM mission, vertical accuracy, interferometry, digital elevation model. 


\section{INTRODUÇÃO}

Os modelos digitais de elevação (MDEs) fornecem informações sobre o terreno ou superfície e são ferramentas importantes em uma vasta gama de aplicações, permitindo o planejamento e execução de projetos, tais como áreas de inundação (SUWANDANA et al 2012), inventários de geleiras (FREY \& PAUL 2012) e Geomorfologia (GROHMANN et al., 2008) entre muitos outros. A disponibilização gratuita de MDE pelos órgãos públicos também fomenta a utilização dessa ferramenta (BIAS et al., 2010, IORIO et al., 2012).

Esses modelos matemáticos tridimensionais do mundo real permitem obter informações sobre volumes, áreas ou distâncias das regiões que representam, sendo obtidos por processos fotogramétricos, cartas topográficas ou sensoriamento remoto (MICELI et al., 2011). A obtenção do MDE a partir da fotogrametria e/ou sensoriamento remoto reduz o trabalho de campo, obtendo informações de extensas áreas em menor custo e tempo (COELHO FILHO \& BRITO, 2007).

Dentre vários modelos, destaca-se o modelo proveniente da missão Shuttle Radar Topographic Mission (SRTM) realizada em conjunto com a National Aeronautics and Space and Administration (NASA) e National GeospatialIntelligence Agency (NGA), com duração de 11 dias, em que foram obtidos dados topográficos sobre $80 \%$ da superfície terrestre entre os paralelos $60^{\circ} \mathrm{N}$ e $56^{\circ} \mathrm{S}$ (USGS, 2015). O SRTM possui resoluções de 90m ou 30m, mas esta última só passou a ser livremente disponibilizada a partir do final de 2014 (BROCHADO, 2015), não sendo objeto deste estudo. O SRTM com resolução espacial de 90 metros é superior ao modelo Global 30 Arc-Second Elevation (GTOPO30), anteriormente disponível com resolução de $1 \mathrm{~km}$ (AZIZIAN et al., 2015). Os dados SRTM têm sido processados por diversas instituições a fim de melhorar a qualidade final do produto, tais como: 
Centro Nacional de Pesquisa de Monitoramento por Satélite da EMBRAPA, no escopo da Coleção "Brasil em Relevo" (MIRANDA, 2005), e os dados do Projeto TOPODATA disponibilizado pelo Instituto Nacional de Pesquisas Espaciais (INPE). Cabe ressaltar que o SRTM é um dado interferométrico obtido da superfície terrestre e não necessariamente do terreno, portanto em região de floresta densa os dados correspondem à copa das árvores (BROCHADO, 2015).

Dessa forma, para o emprego adequado é necessário que se conheça a acurácia altimétrica em diferentes regiões de estudo, estimando as variações em função do tipo de relevo e da cobertura vegetal (MUKHERJEE et al., 2013). Notadamente no Brasil, temos o exemplo da região amazônica, que possui características ímpares de relevo e densa vegetação (SANTOS et al., 2006).

Nesse escopo, nota-se um esforço científico em determinar quais são as precisões em diversas regiões do mundo, como mostrado na Figura 1 e no Quadro 1 (SANTOS et al., 2006; BERRY et al, 2007; SHORTRIDGE \& MESSINA, 2011; MUKHERJEE et al., 2013; ATHMANIA \& ACHOUR 2014). A coluna "referência" do quadro 1 mostra que o SRTM vem sendo estudado de forma contínua no mundo ao longo de, pelo menos, uma década, sendo mais uma informação que corrobora o valor que o conhecimento de tais dados representa.

Boa parte dos trabalhos utiliza como indicadores estatísticos o erro médio e o desvio-padrão (quadro 1), sendo que alguns utilizam a raiz quadrada do erromédio quadrático (RMSE).

Diferentes fontes de informações são utilizadas para mensurar as precisões do modelo SRTM como dados medidos em campo por topografia ou rastreio GNSS (IORIO et al., 2012; SANTOS et al., 2006; GOROKHOVICH \&VOUSTIANIOUK, 2006) ou bases cartográficas com escalas maiores (por exemplo1:10.000 ou 1:25.000) 
obtidas por meio de restituições aerofotogramétricas, dados Laser ou de satélites (NOBREGA et al., 2005; BERRY, et al., 2007; SIART, et al., 2009; FREY et al., 2012). A coluna "Insumos" mostra as diferentes fontes de dados e métodos para a determinação do erro.

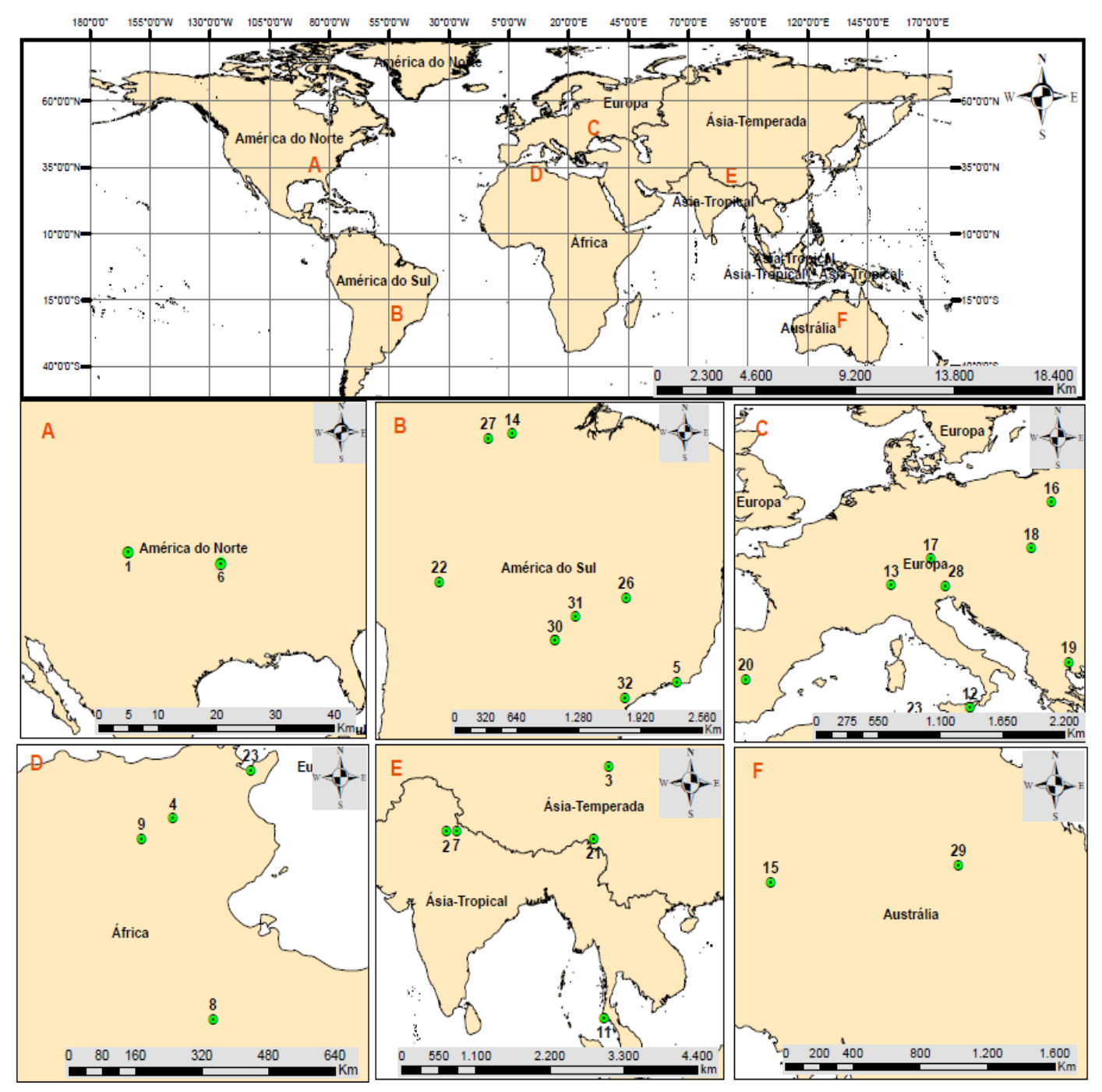

Figura 1 - - Pontos de estudo sobre a acurácia do Modelo SRTM no Mundo. 
Quadro 1- Resumo de estudos que determinam os erros de acurácia de dados SRTM

localizados na Figura 1.

\begin{tabular}{|c|c|c|c|c|c|}
\hline Número & Referência & Local & Modelo & Insumo & Resultados \\
\hline $\mathbf{0}$ & $\begin{array}{l}\text { BERRY et al } \\
\text { (2007). }\end{array}$ & Global & SRTM V2 & Satélite ERS-1. & $\begin{array}{c}\text { Erro médio: } 3,60 \mathrm{~m} \\
\text { Desvio-Padrão: } 16,16 \mathrm{~m} \text {. }\end{array}$ \\
\hline 1 & $\begin{array}{l}\text { SHORTRIDGE \& } \\
\text { MESSINA (2011). }\end{array}$ & EUA & SRTM-V2 & $\begin{array}{l}\text { National Elevation } \\
\text { Dataset (NED) }\end{array}$ & $\begin{array}{l}\text { Erro médio: 2,0 m Desvio- } \\
\text { Padrão: } 8,3 \mathrm{~m} .\end{array}$ \\
\hline 2 & $\begin{array}{l}\text { MUKHERJEE et al } \\
\text { (2013). }\end{array}$ & $\begin{array}{l}\text { Shiwalik } \\
\text { Himalaya, }\end{array}$ & $\begin{array}{c}\text { CGIAR-CSI SRTM } \\
\text { v4.1 }\end{array}$ & $\begin{array}{l}\text { Ground Control } \\
\text { Points (GCPs) }\end{array}$ & $\begin{array}{l}\text { Erro médio: }-2,94 \mathrm{~m} \\
\text { RMSE: } 9,20 \mathrm{~m} .\end{array}$ \\
\hline 3 & Y. Liu (2008). & China & NASA SRTM3 & $\begin{array}{c}\text { Mapa topográfico } \\
1: 25.000\end{array}$ & $\begin{array}{c}\text { Erro médio: }-6,635 \mathrm{~m} \\
\text { Desvio-Padrão: } 29,16 \mathrm{~m} \text {. }\end{array}$ \\
\hline 4 & $\begin{array}{l}\text { CHAIEB et al } \\
(2016)\end{array}$ & $\begin{array}{c}\text { Kasserini, } \\
\text { Tunisia }\end{array}$ & SRTM version 4.1 & $\begin{array}{l}\text { Ground Control } \\
\text { Points (GCPs) }\end{array}$ & $\begin{array}{c}\text { Erro médio: }-1,85 \mathrm{~m} \\
\text { Desvio-Padrão: } 9,41 \mathrm{~m} .\end{array}$ \\
\hline 5 & $\begin{array}{l}\text { MICELI et al } \\
\text { (2011). }\end{array}$ & $\begin{array}{c}\text { Rio de janeiro, } \\
\text { Brasil }\end{array}$ & SRTM 1 & $\begin{array}{c}\text { Carta pográfica } \\
1: 10.000 .\end{array}$ & $\begin{array}{l}90 \% \text { menores que } 15,00 \mathrm{~m} \text {. } \\
\text { RMSE de } 8,86 \mathrm{~m} \text {. }\end{array}$ \\
\hline 6 & $\begin{array}{l}\text { ROBINSON et al } \\
\text { (2014). }\end{array}$ & EUA & $\begin{array}{c}\text { CGIAR-CSI SRTM } \\
\text { v4.1 }\end{array}$ & $\begin{array}{l}\text { Ground Control } \\
\text { Points (GCPs) }\end{array}$ & $\begin{array}{l}\text { Erro médio: 1,66 m } \\
\text { RMSE 4,15m. }\end{array}$ \\
\hline 7 & $\begin{array}{c}\text { DATTA\& } \\
\text { KIRCHNER (2010) }\end{array}$ & Índia & $\begin{array}{l}\text { SRTM- the } \\
\text { University of } \\
\text { Maryland. }\end{array}$ & $\begin{array}{l}\text { Ground Control } \\
\text { Points (GCPs) }\end{array}$ & $\begin{array}{c}\text { Erro médio: }-12,56 \mathrm{~m} \\
\text { Desvio-Padrão: } 51,37 \mathrm{~m} \text {. }\end{array}$ \\
\hline 8 & $\begin{array}{c}\text { ATHMANIA \& } \\
\text { ACHOUR (2014). }\end{array}$ & $\begin{array}{l}\text { Anaguid, } \\
\text { Tunisia }\end{array}$ & $\begin{array}{c}\text { CGIAR-CSI SRTM } \\
\text { v4.1 }\end{array}$ & RTK-DGPS & $\begin{array}{l}\text { Erro médio: 2,9 m Desvio- } \\
\text { Padrão: } 4,6 \mathrm{~m} \text {. }\end{array}$ \\
\hline 9 & $\begin{array}{c}\text { ATHMANIA \& } \\
\text { ACHOUR (2014). }\end{array}$ & $\begin{array}{l}\text { Tebessa, } \\
\text { Tunisia }\end{array}$ & $\begin{array}{c}\text { CGIAR-CSI SRTM } \\
\text { v4.1 }\end{array}$ & RTK-DGPS & $\begin{array}{c}\text { Erro médio: 0,48 m } \\
\text { Desvio-Padrão: } 8,4 \mathrm{~m} \text {. }\end{array}$ \\
\hline 10 & $\begin{array}{c}\text { GOROKHOVICH } \\
\& \\
\text { VOUSTIANIOUC } \\
\text { K }(2006) .\end{array}$ & $\begin{array}{l}\text { CatskillMounta } \\
\text { ins, EUA }\end{array}$ & CGIAR-CSI SRTM & $\begin{array}{l}\text { Ground Control } \\
\text { Points (GCPs) }\end{array}$ & $\begin{array}{c}\text { Erro médio: } 7,58 \mathrm{~m} \\
\text { Desvio-Padrão: } 8,09 \mathrm{~m} \text {. }\end{array}$ \\
\hline 11 & $\begin{array}{c}\text { GOROKHOVICH } \\
\& \\
\text { VOUSTIANIOUC } \\
\text { K }(2006) .\end{array}$ & $\begin{array}{l}\text { Phuket, } \\
\text { Tailândia. }\end{array}$ & CGIAR-CSI SRTM & $\begin{array}{l}\text { Ground Control } \\
\text { Points (GCPs) }\end{array}$ & $\begin{array}{c}\text { Erro médio: } 4,07 \mathrm{~m} \\
\text { Desvio-Padrão: } 4,01 \mathrm{~m} \text {. }\end{array}$ \\
\hline 12 & $\begin{array}{l}\text { TARQUINI et al } \\
\text { (2012). }\end{array}$ & Itália & SRTM-JPL-NASA & LIDAR & RMSE : 7,78m \\
\hline 13 & $\begin{array}{l}\text { FREY \& PAUL } \\
\text { (2012). }\end{array}$ & Suiça & SRTM3 & $\begin{array}{c}\text { DHM25 } \\
\text { (swisstopo). }\end{array}$ & $\begin{array}{c}\text { Erro médio: } 2,23 \mathrm{~m} \\
\text { Desvio-Padrão: } 21,64 \mathrm{~m} \text {. }\end{array}$ \\
\hline 14 & $\begin{array}{l}\text { MICELI et al } \\
\text { (2011). }\end{array}$ & $\begin{array}{l}\text { Amazônia, } \\
\text { Brasil }\end{array}$ & SRTM 1 & $\begin{array}{l}\text { Ground Control } \\
\text { Points (GCPs) }\end{array}$ & $\begin{array}{l}90 \% \text { menores que } 25,00 \mathrm{~m} \text {. } \\
\text { RMSE de } 11,70 \mathrm{~m} .\end{array}$ \\
\hline 15 & $\begin{array}{l}\text { M. Rexer \& C. Hirt } \\
(2014)\end{array}$ & Austrália & $\begin{array}{c}\text { CGIAR-CSI SRTM } \\
\text { v4.1 }\end{array}$ & $\begin{array}{l}\text { Ground Control } \\
\text { Points (GCPs) }\end{array}$ & $\begin{array}{c}\text { Erro médio: } 3,04 \mathrm{~m} \\
\text { Desvio-Padrão: } 3,22 \mathrm{~m} \text {. }\end{array}$ \\
\hline 16 & $\begin{array}{l}\text { A. K. Karwel \& I. } \\
\text { Ewiak (2008) }\end{array}$ & Polônia & SRTM & $\begin{array}{l}\text { Ground Control } \\
\text { Points (GCPs) }\end{array}$ & $\begin{array}{c}\text { RMSE : 2,9m(plano) } \\
\text { RMSE }=5,4 \mathrm{~m}(\text { montanha }) .\end{array}$ \\
\hline 17 & $\begin{array}{c}\text { H.Jörn \& W. Diana } \\
(2008)\end{array}$ & $\begin{array}{c}\text { Sul da } \\
\text { Alemanha }\end{array}$ & SRTM-JPL-NGA & $\begin{array}{l}\text { Ground Control } \\
\text { Points (GCPs) }\end{array}$ & Desvio-Padrão: $3,90 \mathrm{~m}$. \\
\hline 18 & $\begin{array}{l}\text { K. NATALIA \& K. } \\
\text { JACEK (2014) }\end{array}$ & Polônia & SRTM -version 4 & $\begin{array}{c}\text { DEM- } \\
\text { Cartographic } \\
\text { Inventory } \\
\end{array}$ & $\begin{array}{c}\text { Erro médio: } 4,31 \mathrm{~m} \\
\text { Desvio-Padrão: } 14,09 \mathrm{~m} \text {. }\end{array}$ \\
\hline 19 & $\begin{array}{c}\text { M. ANTONIOS et } \\
\operatorname{al}(2010)\end{array}$ & Grécia & SRTM.V4 & $\begin{array}{l}\text { KGPS coletados } \\
\text { com veículo } \\
\text { (GPS). }\end{array}$ & $\begin{array}{c}\text { Erro médio: } 0,30 \mathrm{~m} \\
\text { Desvio-Padrão: } 6,40 \mathrm{~m} \text {. }\end{array}$ \\
\hline 20 & $\begin{array}{l}\text { G. ALVARO et al } \\
(2011)\end{array}$ & Espanha & SRTM version 4.1 & $\begin{array}{c}\text { Mapa topográfico } \\
1: 10.000\end{array}$ & RMSE: $6,10 \mathrm{~m}$. \\
\hline 21 & $\begin{array}{c}\text { WANG, W. et al } \\
(2012)\end{array}$ & Tibet & CIGIAR_SRTM & $\begin{array}{c}\text { Mapa topográfico } \\
1: 50.000\end{array}$ & $\begin{array}{l}\text { Erro médio: 5,3 m Desvio- } \\
\text { Padrão: } 12,2 \mathrm{~m} .\end{array}$ \\
\hline 22 & $\begin{array}{l}\text { MUKUL et al } \\
(2015)\end{array}$ & $\begin{array}{l}\text { América do } \\
\text { Sul }\end{array}$ & SRTM version 4.1 & $\begin{array}{l}\text { Ground Control } \\
\text { Points (GCPs) }\end{array}$ & $\begin{array}{c}\text { Erro médio: 5,2m Desvio- } \\
\text { Padrão:10,2m. }\end{array}$ \\
\hline 23 & $\begin{array}{l}\text { OUERGHI et al } \\
(2015)\end{array}$ & $\begin{array}{l}\text { Grombalia, } \\
\text { Tunísia }\end{array}$ & SRTM version 4.1 & $\begin{array}{c}\text { Mapa topográfico } \\
1: 25.000\end{array}$ & $\begin{array}{c}\text { Erro médio: } 0,76 \mathrm{~m} \\
\text { Desvio-Padrão: } 47,46 \mathrm{~m} \text {. }\end{array}$ \\
\hline
\end{tabular}




\begin{tabular}{|c|c|c|c|c|c|}
\hline 24 & $\begin{array}{l}\text { SUWANDANA et } \\
\text { al (2012). }\end{array}$ & Indonésia & SRTM v4.1 & RTK-DGPS & RMSE 3,250m. \\
\hline 25 & $\begin{array}{l}\text { MUKUL et al } \\
(2015)\end{array}$ & Global & SRTM v4.1 & $\begin{array}{l}\text { Ground Control } \\
\text { Points (GCPs) }\end{array}$ & $\begin{array}{c}\text { Erro médio: } 8,0 \mathrm{~m} \\
\text { Desvio-Padrão: } 8,3 \mathrm{~m} .\end{array}$ \\
\hline 26 & $\begin{array}{l}\text { MOURA et al } \\
\quad(2014)\end{array}$ & $\begin{array}{c}\text { Distrito } \\
\text { Federal, Brasil }\end{array}$ & SRTM v4 & $\begin{array}{c}\text { Mapa topográfico } \\
1: 10.000\end{array}$ & $\begin{array}{c}\text { Erro médio: } 3,14 \mathrm{~m} \\
\text { Desvio-Padrão: } 4,06 \mathrm{~m} \text {. }\end{array}$ \\
\hline 27 & $\begin{array}{l}\text { SANTOS et al } \\
(2006)\end{array}$ & $\begin{array}{l}\text { Amazônia, } \\
\text { Brasil }\end{array}$ & SRTM-3 & $\begin{array}{l}\text { Ground Control } \\
\text { Points (GCPs) }\end{array}$ & Desvio-Padrão: $11,06 m$. \\
\hline 28 & $\begin{array}{c}\text { Ludwig \& } \\
\text { Schneider (2006) }\end{array}$ & Alemanha & $\begin{array}{c}\text { SRTM(German } \\
\text { Aerospace Agency) }\end{array}$ & $\begin{array}{c}\text { Mapa topográfico } \\
1: 25.000\end{array}$ & $\begin{array}{l}\text { Erro médio: 11,98 m } \\
\text { RMSE: } 36,21 \mathrm{~m} .\end{array}$ \\
\hline 29 & $\begin{array}{l}\text { JARIHANI et al } \\
(2015)\end{array}$ & Austrália & SRTM(30/90m) & $\begin{array}{l}\text { Ground Control } \\
\text { Points (GCPs) }\end{array}$ & Desvio-Padrão: $1,84 \mathrm{~m}$. \\
\hline 30 & IORIO et al (2011) & $\begin{array}{l}\text { Pantanal, } \\
\text { Brasil }\end{array}$ & SRTM v4 & $\begin{array}{l}\text { Ground Control } \\
\text { Points (GCPs) }\end{array}$ & E.M.Q: 16,69m. \\
\hline 31 & $\begin{array}{l}\text { MEDEIROS et al } \\
\text { (2009) }\end{array}$ & Goiás-Brasil & SRTM-EMBRAPA & $\begin{array}{l}\text { Ground Control } \\
\text { Points (GCPs) }\end{array}$ & $\begin{array}{c}\text { Erro médio: } \mathbf{- 3 , 0 m} \\
\text { Desvio-Padrão:10,0m. }\end{array}$ \\
\hline 32 & $\begin{array}{l}\text { NÓBREGA et al } \\
(2005)\end{array}$ & $\begin{array}{l}\text { São Paulo- } \\
\text { Brasil }\end{array}$ & SRTM & $\begin{array}{c}\text { Fotogrametria } \\
1: 8.000\end{array}$ & $\begin{array}{c}\text { Erro médio: } 14,23 \mathrm{~m} \\
\text { Desvio-Padrão:13,73m. }\end{array}$ \\
\hline
\end{tabular}

A avaliação de acurácia dos dados da missão SRTM ainda são feitas, em sua maioria em pequenas regiões (SANTOS et al., 2006; Bias et al 2010; MICELI et al., 2011; IORIO et al., 2012; ATHMANIA \& ACHOUR, 2014) e poucos trabalhos realizam aferições em escala global ou regional. E também não avaliam todos os modelos que foram submetidos a tratamento de dados, como o elaborado por Jhonatan de Ferranti disponível no site Viewfinder Panoramas (TAIT, 2010).

Dentro deste contexto, o presente trabalho possui como objetivo identificar e comparar a acurácia vertical do modelo SRTM, obtido por diferentes fontes, para todo o Brasil por meio de pontos medidos em campo, classificando por faixa de 4 graus de latitude segundo o Padrão de Exatidão Cartográfica (PEC) correspondente, nos termos do Decreto 89.817/84 que estabelece as normas gerais da cartografia Nacional. Especificamente, pretende-se: (1) utilizar 1.087 pontos medidos em campo distribuídos em todo território brasileiro para que os resultados sejam representativos e forneçam uma boa sensibilidade do comportamento da acurácia altimétrica dos modelos avaliados; (2) comparar 4 diferentes modelos que tenham como origem os dados fornecidos pelo SRTM a saber: modelo disponibilizado pela EMBRAPA, 
modelo HydroSHEDS fornecido pelo USGS, CGIAR_CSI, e Jhonatan de Ferranti; (3) classificar os modelos de acordo com o PEC, por faixa de 4 graus de latitude e para todo país; (4) verificar o comportamento do erro altimétrico em relação à declividade; e (5) mostrar a influência da vegetação na variação dos erros.

\section{2. Área de Estudo}

O território brasileiro foi dividido em faixas com quatro graus de latitude, visando uma distribuição homogênea dos dados de campo e minimizando a possibilidade de ocorrência de grandes áreas sem medições, além de ser similar à divisão feita no mapeamento sistemático brasileiro para escala 1:1.000.000 (IBGE, 2016). A escolha dos pontos também considerou abranger o máximo de fusos UTM que cobrem o território brasileiro: 20, 21, 22, 23 e 24 (Figura 2), não havendo pontos nos fusos 18,19 e 25.

Assim, buscou-se que as diferentes regiões do país fossem contempladas, considerando variações do relevo, vegetação e ações humanas. 


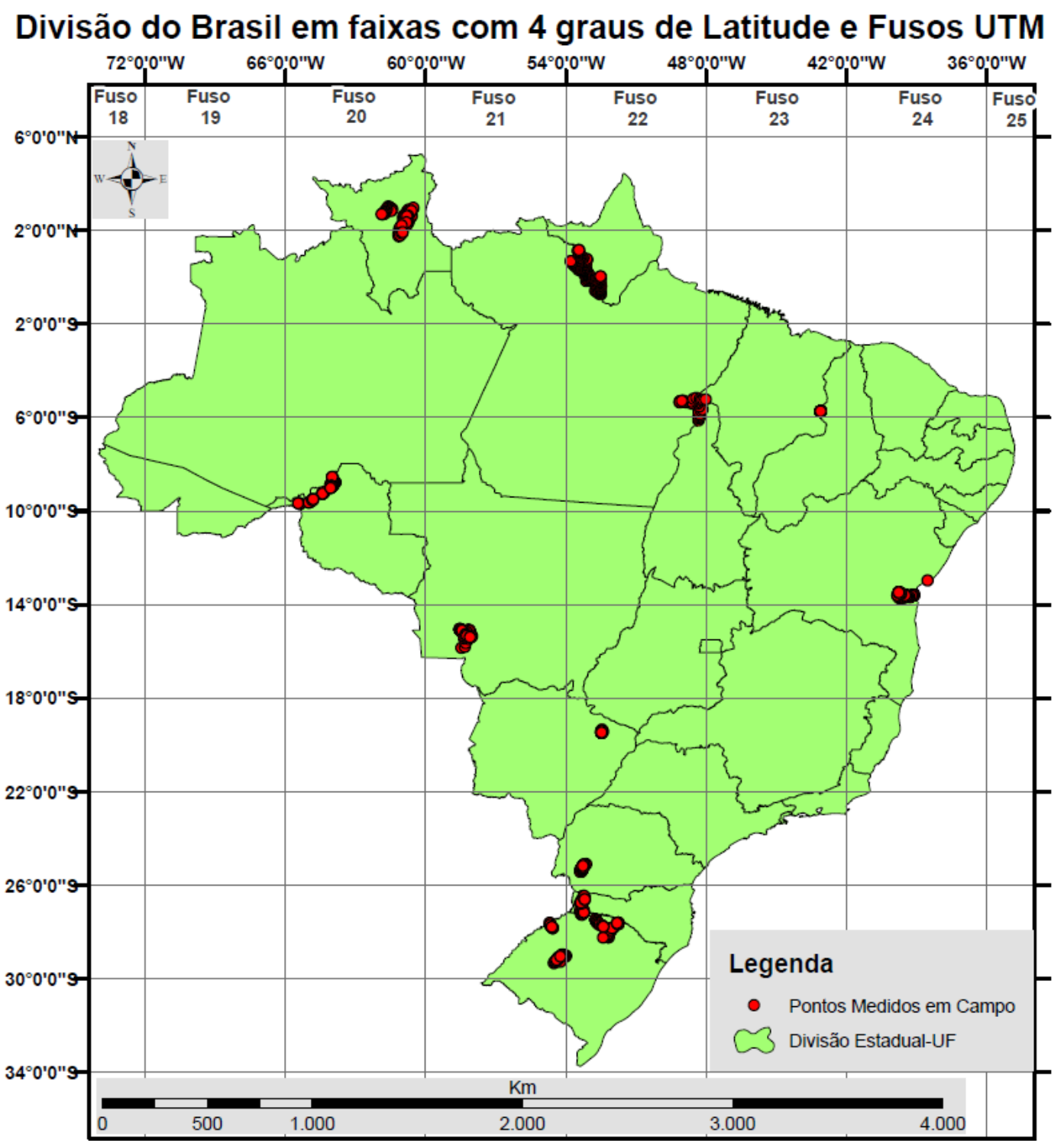

Figura 2 - Brasil dividido em faixas com 4 graus de latitude, Fusos UTM e a localização dos pontos medidos em campo.

As regiões selecionadas buscaram incluir diferentes níveis de altitudes com o objetivo de avaliar a sua influência. O ponto mais alto medido foi na altitude de 829,09 metros e o mais baixo na altitude de 0,74 metros. Houve o intuito de percorrer o máximo possível de fusos UTM e a maior faixa possível de latitudes em território brasileiro, buscando as mais variadas formas de relevo e vegetação. 


\section{Materiais e Métodos}

3.1 Pontos Medidos no Terreno

Os pontos medidos em campo (medição diretamente no terreno) foram obtidos com rastreadores GNSS (Global Navigation Satellite System) (Figura 3), sendo utilizados para o apoio básico às restituições aerofotogramétricas ou trabalhos de topografia com Nivelamento Geométrico ou Trigonométrico. Esses pontos subsidiaram estudos cartográficos de inventários hidrelétricos ou projetos básicos de usinas hidrelétricas aprovados pela Agência Nacional de Energia Elétrica (ANEEL) em todo o Brasil. Há também 32 pontos medidos com GNSS pelo autor nas proximidades das Usinas Hidrelétricas Santo Antônio e Jirau, distribuídos desde a cidade de Porto Velho até Abunã (fronteira com a Bolívia).

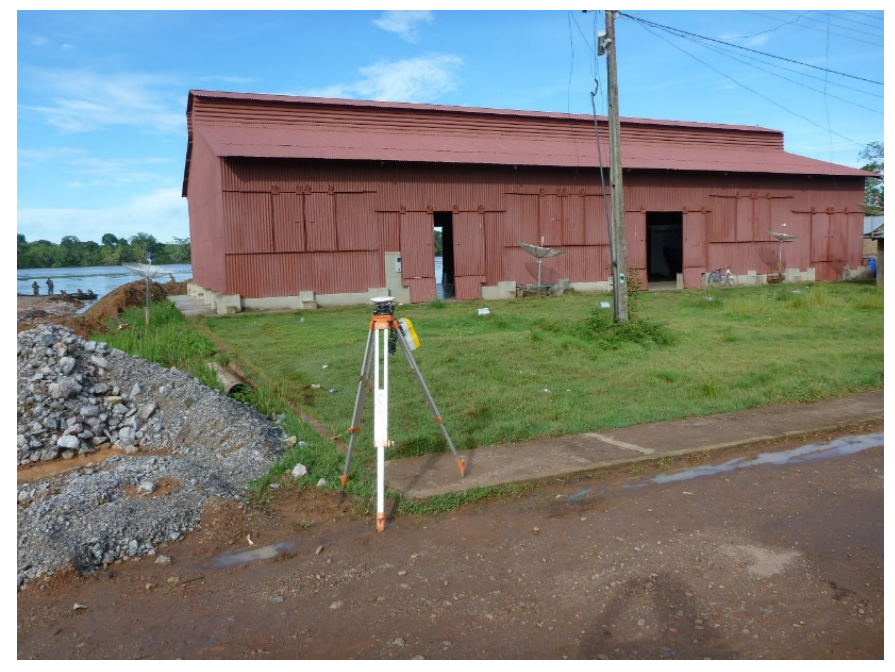

Figura 3 - Ponto medido com receptor Geodésico em Abunã-RO, Brasil.

Os dados foram obtidos no Centro de Documentação da ANEEL (CEDOC) onde estão os projetos básicos de usinas hidrelétricas e/ou inventários hidrelétricos aprovados pela Agência (ANEEL, 2015). Estes dados estão divididos por faixas de $4^{\circ}$ de latitude para todo o Brasil. Nos documentos cartográficos, foram extraídos os pontos de apoio à restituição (pontos de controle) ou outros marcos implantados no terreno por meio de rastreio GNSS ou trabalhos de topografia com 
Nivelamento Geométrico ou Trigonométrico. Os dados foram uniformizados para o sistema de referência, haja vista que a maioria dos dados estão em SAD69 e devem ser transformados, compatibilizando-os, assim, com o Sistema de Referência único para este estudo (SIRGAS2000). Foram obtidos ao menos 50 pontos de campo, em sua maioria nos estudos de inventários hidrelétricos provados pela ANEEL, para avaliar o SRTM em cada faixa de Latitude. A figura 4 mostra os pontos de controle ou pontos "HV" (COELHO FILHO \& BRITO, 2007) utilizados para obter a restituição para o inventário do rio das Caveiras em Santa Catarina.

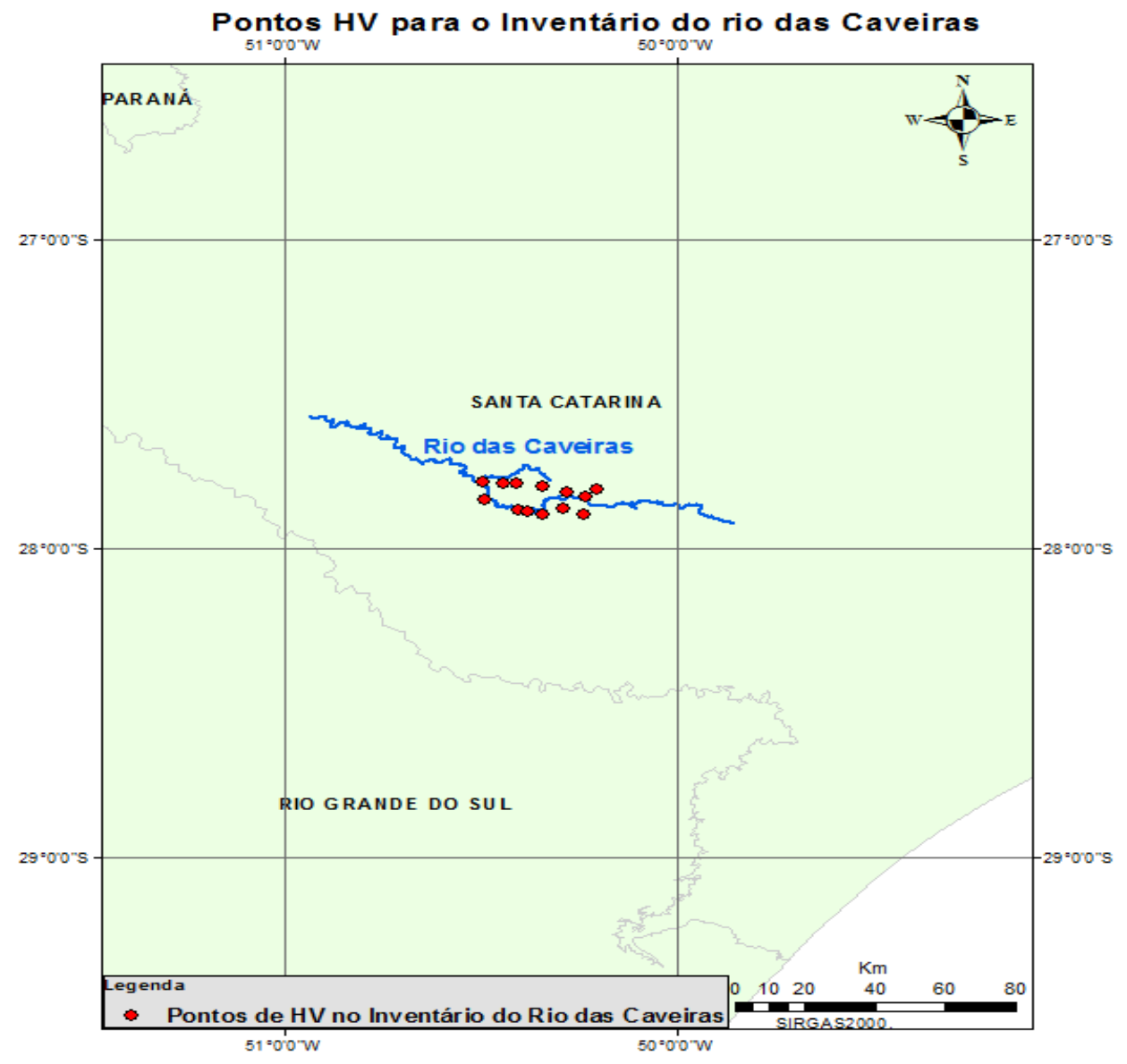

Figura 4 - Exemplo de Pontos do inventário do rio das Caveiras coletados no CEDOC da ANEEL abrangendo a região entre os paralelos $30^{\circ} \mathrm{S}$ e $26^{\circ} \mathrm{S}$. 


\subsection{Modelos Avaliados}

O modelo SRTM disponibilizado gratuitamente pelo Centro Nacional de Pesquisa de Monitoramento por Satélite da EMBRAPA possui os dados em formato GEOTIFF e quadrículas de $1^{\circ}$ (Latitude) por 1³0’ (Longitude), com 90m de resolução espacial, possuindo uma prévia correção dos erros de depressões espúrias, picos anômalos e pontos ou áreas com ausência de dados (MIRANDA, 2005). Esse modelo pode ser utilizado para obtenção de altitudes com acurácia compatível com a escala 1:100.000 ou delimitação automática de bacias hidrográficas (MEDEIROS et al, 2009; MICELI et al, 2011).

O modelo HydroSHEDS (Hydrological data and maps based on SHuttle Elevation Derivatives at multiple Scales) (USGS, 2016) é um modelo hidrologicamente corrigido, oferecendo dados como linhas de drenagem, limites de bacias hidrográficas e topologia de rios (LEHNER et al, 2006; DASGUPTA, 2011; LEHNER, 2012; AMARAL et al, 2013; MELO, 2013.). Os dados são disponibilizados em formato Raster (extensão “. Con”) em quadrículas de $5^{\circ}$ por $5^{\circ}$, com 90m de resolução espacial.

O Modelo fornecido pelo CGIAR-CSI, V4.1, (Consultative Group for International Agricultural Research-Consortium for Spatial Information) é disponibilizado em quadrículas de $5^{\circ}$ por $5^{\circ}$, com $90 \mathrm{~m}$ de resolução espacial e no formato GEOTIFF. Os dados foram processados para cobrir áreas que ainda possuíam vazios de informação, consistindo em uma evolução da versão anterior, com aplicações como cálculo de declividade, modelagem de inundação e obtenção de elevações de montanhas (WANG et al, 2012; KOLECKA \& KOZAK, 2014; REXER \& C. HIRT 2014). 
O Modelo fornecidos por Jhonatan de Ferranti é disponibilizado no formato "HGT" e resolução espacial de 90m, sendo os recortes dados em quadrículas de $1^{\circ}$ por $1^{\circ}$ e reprocessados para cobrir regiões vazias, principalmente os vazios localizados em regiões montanhosas (OPENDEM, 2016; TAIT, 2010; TERRAINMAP, 2016; VTERRAIN, 2016). Além disso, esse modelo foi utilizado como base no Modelo fornecido pelo CGIAR-CSI, V4.1, também comparado neste estudo, para regiões montanhosas na Ásia Central, China e Europa (CGIAR-CSI, 2016).

\subsection{Processamento de dados}

Os pontos foram reprojetados para o mesmo Sistema de Referência SIRGAS2000. A partir desses Modelos do SRTM em formato Raster, gerou-se o Triangulated Irregular Network (TIN) a fim de calcular a altitude de cada ponto no MDE, correspondendo ao ponto medido em campo. Ressalta-se que existem diversos métodos para a construção de um MDE, contudo, basicamente, utilizam-se a grade regular retangular (GRID) e o TIN (FERNANDES \& MENEZES, 2005), com o uso de diversos interpoladores (CAMARA et al., 2001). Neste estudo, optou-se pelo uso do TIN, pois os terrenos estudados apresentam, em geral, variação topográfica considerável, sendo o TIN adequado para retratar essas variações (FERNANDES \& MENEZES, 2005). De posse dessas duas altitudes ortométricas, adotou-se o erro do ponto como sendo a diferença simples entre o valor obtido por meio do SRTM (ZSRTM) subtraído do valor da altitude do respectivo homólogo medido em campo (Hcampo), como mostram a Figura 5 e quadro 2. 


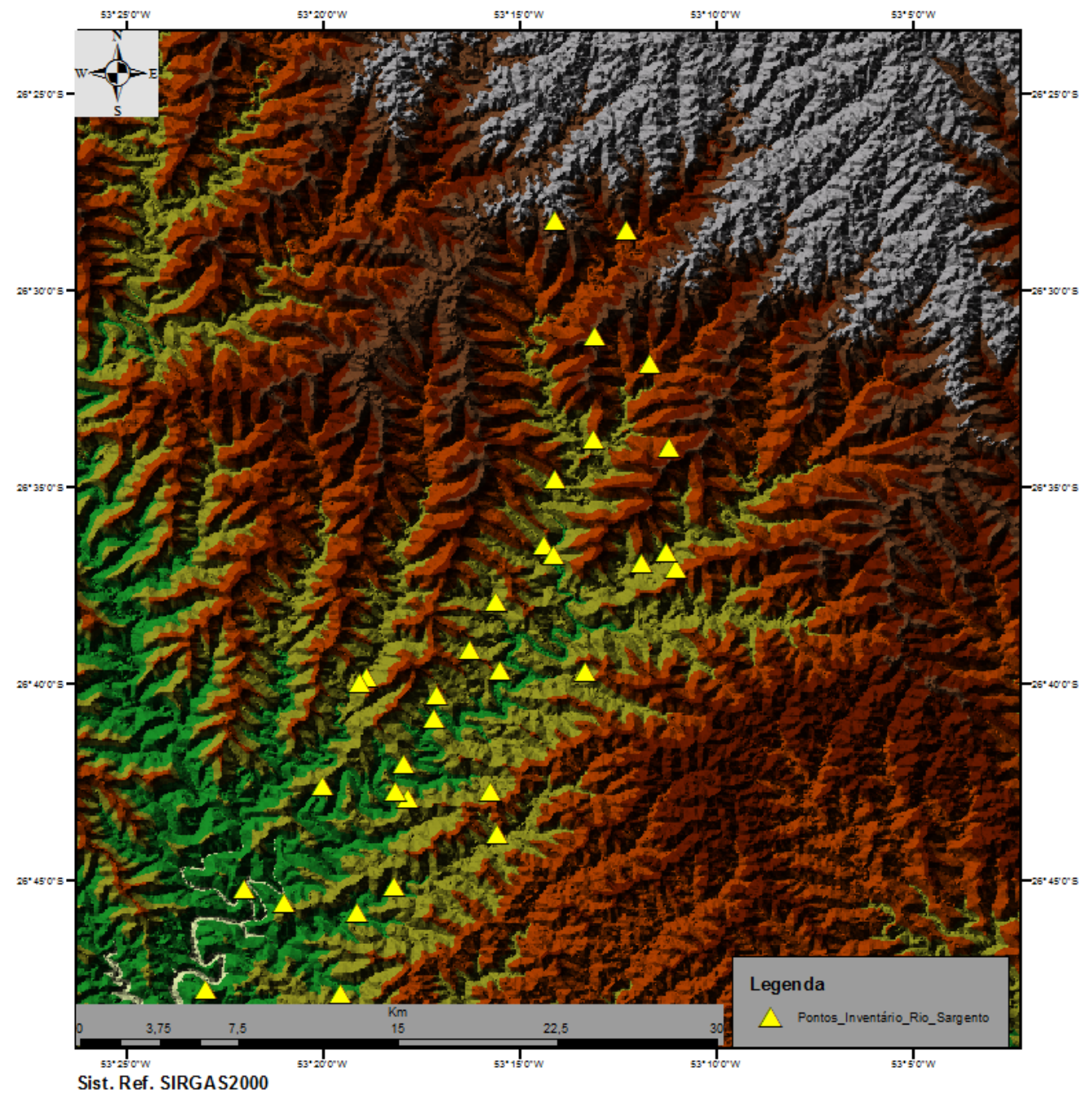

Figura 5 - Exemplo de Pontos do inventário do rio Sargento sobreposto ao TIN obtido por meio do SRTM na região entre os paralelos $30^{\circ} \mathrm{S}$ e $26^{\circ} \mathrm{S}$. 


\begin{tabular}{|c|c|c|c|}
\hline Faixa de Latitude & Hcampo & Zsrtm & Zsrtm - Hcampo \\
\hline \multirow{19}{*}{$06-02 S$} & 104,764 & 108,7458 & 3,9818 \\
\hline & 99,595 & 107,4562 & 7,8612 \\
\hline & 103,715 & 102,2168 & $-1,4982$ \\
\hline & 103,933 & 104,1525 & 0,2195 \\
\hline & 103,331 & 109,135 & 5,8040 \\
\hline & 101,542 & 102,7039 & 1,1619 \\
\hline & 99,132 & 99,43642 & 0,3044 \\
\hline & 97,581 & 105,1012 & 7,5202 \\
\hline & 96,552 & 100,0167 & 3,4647 \\
\hline & 94,514 & 96,25007 & 1,7361 \\
\hline & 94,008 & 94,99226 & 0,9843 \\
\hline & 93,507 & 97,60388 & 4,0969 \\
\hline & 93,165 & 101,9024 & 8,7374 \\
\hline & 95,945 & 102,1414 & 6,1964 \\
\hline & 82,245 & 86,66293 & 4,4179 \\
\hline & 81,652 & 84,61939 & 2,9674 \\
\hline & 95,14 & 98,15143 & 3,0114 \\
\hline & 96,255 & 102,1798 & 5,9248 \\
\hline & 97,543 & 102,7922 & 5,2492 \\
\hline
\end{tabular}

Quadro 2 - Exemplo de cálculo de erros na faixa $02^{\circ}-06^{\circ} \mathrm{S}$.

Os erros de cada ponto foram aglutinados em faixa de Latitude para o cálculo do desvio-padrão e média. Também a acurácia foi avaliada a partir da definiçãa de um valor limite no qual $90 \%$ dos erros comparados estão abaixo deste valor. Assim, dispõe-se dos parâmetros necessários para avaliar cada MDE, conforme o PEC estabelecido no Decreto 89.817/84.

Os valores do PEC classificam o Modelo nas Classes "A", "B" e "C", sendo o "A" o produto de maior acurácia. Importante ressaltar que as precisões utilizadas nessa classificação estão defasadas em termos das tecnologias disponíveis e possibilidades mais precisas de medição em relação ao que existia na época de sua edição, há mais de 30 anos. Contudo, o fato de exprimir um critério de fácil mensuração e de conhecimento difundido no ambiente acadêmico brasileiro faz com que seja uma boa opção para expressar o comportamento do Modelo SRTM no Brasil, facilitando comparações dos resultados com outros trabalhos (SANTOS et al.,2006; 
MICELI et al., 2011). Por isso, privilegiando a possibilidade de comparações com outros estudos e sabendo que os parâmetros aqui expostos poderiam ser utilizados para a classificação dos modelos no PEC para Produtos Cartográficos Digitais,PECPCD, como feito por MOURA et al., 2014, optou-se por realizar as duas classificações. Contudo, para evitar confusões nas análises feitas, a discussão e a conclusão serão referentes ao PEC prevista no Decreto nº 89.817/1984, pois é aquele que aparece na maior quantidade nos estudos observados neste artigo.

O quadro 3 mostra a classificação quanto ao PEC para as escalas 1:50.000 e 1:100.000 referente ao Decreto 89.817/84 e o quadro 4, referente ao PEC-PCD constante das Especificações Técnicas para Aquisição de Dados Geoespaciais Vetoriais, versão 2.1.3, já homologada pela Comissão Nacional de Cartografia (CONCAR).

Quadro 3- VALORES DO PEC CLASSES “A”, "B” e "C" PARA ESCALAS $1: 100.000$ e $1: 50.000$.

\begin{tabular}{|c|c|c|c|c|}
\hline \multicolumn{5}{|c|}{ PEC ALTIMÉTRICO } \\
\hline \multirow{2}{*}{ Classe } & \multicolumn{2}{|c|}{$1: 50.000$} & \multicolumn{2}{|c|}{$1: 100.000$} \\
\hline & Tolerância & E.M.Q & Tolerância & E.M.Q \\
\hline A & $\begin{array}{l}90 \% \text { dos } \\
\text { pontos } \\
<10,0 \mathrm{~m}\end{array}$ & $6,6 m$ & $\begin{array}{l}90 \% \text { dos } \\
\text { pontos } \\
<25,0 \mathrm{~m}\end{array}$ & $16,6 \mathrm{~m}$ \\
\hline B & $\begin{array}{c}90 \% \text { dos } \\
\text { pontos } \\
<12,0 \mathrm{~m}\end{array}$ & $8,0 m$ & $\begin{array}{c}90 \% \text { dos } \\
\text { pontos } \\
<30,0 \mathrm{~m}\end{array}$ & $20,0 \mathrm{~m}$ \\
\hline C & $\begin{array}{c}90 \% \text { dos } \\
\text { pontos } \\
<15,0 m\end{array}$ & $10,0 \mathrm{~m}$ & $\begin{array}{c}90 \% \text { dos } \\
\text { pontos } \\
<36,6 \mathrm{~m}\end{array}$ & $25,0 \mathrm{~m}$ \\
\hline
\end{tabular}

Fonte: adaptado do Decreto $\mathrm{n}^{\mathrm{o}} 89.817 / 84$ 
Quadro 4- VALORES DO PEC-PCD CLASSES “A”, “B”, “C” E “D” PARA

ESCALAS 1:100.000 e 1:50.000.

\begin{tabular}{|c|c|c|c|c|}
\hline \multicolumn{5}{|c|}{ PEC-PCD ALTIMÉTRICO } \\
\hline \multirow{2}{*}{ Classe } & \multicolumn{2}{|c|}{$1: 50.000$} & \multicolumn{2}{|c|}{$1: 100.000$} \\
\hline & Tolerância & E.M.Q & Tolerância & E.M.Q \\
\hline A & $\begin{array}{l}90 \% \text { dos } \\
\text { pontos } \\
<5,50 \mathrm{~m}\end{array}$ & $3,3 \mathrm{~m}$ & $\begin{array}{c}90 \% \text { dos } \\
\text { pontos } \\
<13,70 \mathrm{~m}\end{array}$ & $8,33 \mathrm{M}$ \\
\hline B & $\begin{array}{c}90 \% \text { dos } \\
\text { pontos } \\
<10,0 \mathrm{~m} \\
\end{array}$ & $6,6 \mathrm{~m}$ & $\begin{array}{c}90 \% \text { dos } \\
\text { pontos } \\
<25,0 \mathrm{~m} \\
\end{array}$ & $16,6 \mathrm{~m}$ \\
\hline C & $\begin{array}{l}90 \% \text { dos } \\
\text { pontos } \\
<12 \text {, } 0 \mathrm{~m}\end{array}$ & $8,0 \mathrm{~m}$ & $\begin{array}{c}90 \% \text { dos } \\
\text { pontos } \\
<30,0 \mathrm{~m}\end{array}$ & $20,0 \mathrm{~m}$ \\
\hline D & $\begin{array}{l}90 \% \text { dos } \\
\text { pontos } \\
<15,0 \mathrm{~m}\end{array}$ & $10,0 \mathrm{~m}$ & $\begin{array}{c}90 \% \text { dos } \\
\text { pontos } \\
<36,6 \mathrm{~m} \\
\end{array}$ & $25,0 \mathrm{~m}$ \\
\hline
\end{tabular}

Fonte: adaptado da ET-ADGV, versão 2.1.3.

Ressalta-se que no Padrão de Exatidão Cartográfica Altimétrica dos Pontos Cotados, MDT, MDE e MDS para a produção de Produtos Cartográficos Digitais (PEC-PCD), constantes do quadro 4, suas classes "B", “C" e "D" correspondem exatamente às classes “A”, "B" e "C" do PEC previsto no Decreto 89.817/84 (DSG, 2011).

Nesse contexto, cabe um esclarecimento de ordem legal: o PEC estabelecido pelo Decreto 89.817/84 não possui primazia sobre o PEC-PCD, haja vista que os dois possuem amparo legal de igual forma, mesmo sendo o primeiro emitido por Decreto do Presidente da República e o segundo, por uma Especificação Técnica da Diretoria de Serviço Geográfico do Exército Brasileiro (DSG). Isso porque o Decreto n²43/1967, em seu Art. $15, \S 1^{\circ}$, número 2, atribui a competência para emissão de Normas Técnicas a serem obedecidas nos trabalhos cartográficos realizados no 
território brasileiro, com escala maiores ou igual a 1:250.000, à Diretoria de Serviço Geográfico.

\section{RESULTADOS}

\subsection{Análise Estatística dos Erros}

Os resultados mostram que a acurácia vertical do SRTM varia consideravelmente entre os modelos avaliados, tendo como destaque a diferença entre os desvios-padrão, na faixa $14^{\circ} \mathrm{S}-10^{\circ} \mathrm{S}$, sendo $12,57 \mathrm{~m}$ para o Modelo CGIAR-CSI e 5,77m para o Modelo de Jhonatan de Ferranti (Quadro 5). Uma vez que os pontos de campo são os mesmos, todos os procedimentos deste estudo foram idênticos para obtenção dos resultados para cada Modelo SRTM e a resolução espacial também é igual para todas as fontes de modelo, as únicas variáveis que os diferenciam são os procedimentos metodológicos aplicados e o processamento realizado por cada fonte antes de sua disponibilização, sendo este o fator que explica tais diferenças.

Quadro 5- Resumo das acurácias Obtidas por Faixa de Latitudes

\begin{tabular}{|c|c|c|c|c|c|c|c|c|c|}
\hline \multirow[t]{2}{*}{ Faixa } & \multirow{2}{*}{\begin{tabular}{|c} 
Pontos \\
medidos \\
em \\
campo
\end{tabular}} & \multicolumn{4}{|c|}{ Erro Médio } & \multicolumn{4}{|c|}{ Desrio-Padrão } \\
\hline & & $\begin{array}{l}\text { CGIAR- } \\
\text { CSI }\end{array}$ & \begin{tabular}{|l} 
SRTM \\
EMBRAPA
\end{tabular} & HydroSHEDS & \begin{tabular}{|l} 
SRTM \\
Ferranti
\end{tabular} & $\begin{array}{l}\text { CGIAR- } \\
\text { CSI }\end{array}$ & \begin{tabular}{|l} 
SRTM \\
EMBRAPA
\end{tabular} & HydroSHEDS & $\begin{array}{l}\text { SRTM } \\
\text { Ferranti }\end{array}$ \\
\hline $02^{\circ} \mathrm{N}-06^{\circ} \mathrm{N}$ & 76 & $-0,4 \mathrm{~m}$ & $-0,07 \mathrm{~m}$ & $-11,64 m$ & $-0,61 \mathrm{~m}$ & 4,36 & $5,46 \mathrm{~m}$ & $8,03 \mathrm{~m}$ & $3,79 \mathrm{~m}$ \\
\hline $02^{\circ} \mathrm{S}-02^{\circ} \mathrm{N}$ & 159 & $13,17 \mathrm{~m}$ & $15,25 \mathrm{~m}$ & $1,97 \mathrm{~m}$ & $12,15 \mathrm{~m}$ & 10,16 & $9,47 \mathrm{~m}$ & $12,56 \mathrm{~m}$ & $8,28 \mathrm{~m}$ \\
\hline $06^{\circ} \mathrm{S}-02^{\circ} \mathrm{S}$ & 51 & $4,44 \mathrm{~m}$ & $4,31 \mathrm{~m}$ & $-14,91 \mathrm{~m}$ & $4,01 \mathrm{~m}$ & 3,38 & $8,99 \mathrm{~m}$ & $8,824 \mathrm{~m}$ & $2,84 \mathrm{~m}$ \\
\hline $10^{\circ} \mathrm{S}-06^{\circ} \mathrm{S}$ & 134 & $1,21 \mathrm{~m}$ & $2,26 \mathrm{~m}$ & $-5,68 \mathrm{~m}$ & $0,3 \mathrm{~m}$ & 6,72 & $8,88 \mathrm{~m}$ & $8,76 \mathrm{~m}$ & $5,37 \mathrm{~m}$ \\
\hline $14^{\circ} \mathrm{S}-10^{\circ} \mathrm{S}$ & 132 & $13,51 \mathrm{~m}$ & $11,15 \mathrm{~m}$ & $9,04 \mathrm{~m}$ & $7,7 \mathrm{~m}$ & 12,57 & $10,29 \mathrm{~m}$ & $12,75 \mathrm{~m}$ & $5,77 \mathrm{~m}$ \\
\hline $18^{\circ} \mathrm{S}-14^{\circ} \mathrm{S}$ & 149 & $8,07 \mathrm{~m}$ & $9,47 \mathrm{~m}$ & $5,39 \mathrm{~m}$ & $7,79 \mathrm{~m}$ & 6,15 & $6,69 \mathrm{~m}$ & $7,02 \mathrm{~m}$ & $4,91 \mathrm{~m}$ \\
\hline $22^{\circ} \mathrm{S}-18^{\circ} \mathrm{S}$ & 69 & $6,72 \mathrm{~m}$ & $8,18 \mathrm{~m}$ & $-4,77 \mathrm{~m}$ & $6,91 \mathrm{~m}$ & 3,25 & $5,50 \mathrm{~m}$ & $5,46 \mathrm{~m}$ & $3,07 \mathrm{~m}$ \\
\hline $26^{\circ} \mathrm{S}-22^{\circ} \mathrm{S}$ & 127 & $10,77 \mathrm{~m}$ & $14,11 \mathrm{~m}$ & $5,33 \mathrm{~m}$ & $9,19 \mathrm{~m}$ & 11,18 & $9,66 \mathrm{~m}$ & $10,18 \mathrm{~m}$ & $5,64 \mathrm{~m}$ \\
\hline $30^{\circ} \mathrm{S}-26^{\circ} \mathrm{S}$ & 190 & $6,03 \mathrm{~m}$ & $7,74 \mathrm{~m}$ & $0,07 \mathrm{~m}$ & $4,91 \mathrm{~m}$ & 10,75 & $14,23 \mathrm{~m}$ & $14,78 \mathrm{~m}$ & $7,88 \mathrm{~m}$ \\
\hline Total (BRASIL) & 1087 & $9,78 \mathrm{~m}$ & $8,96 \mathrm{~m}$ & $0,24 \mathrm{~m}$ & $6,33 \mathrm{~m}$ & 8,16 & $11,20 \mathrm{~m}$ & $12,70 \mathrm{~m}$ & $7,22 \mathrm{~m}$ \\
\hline
\end{tabular}

Além disso, os desvios-padrão de 12,56m (HydroSHEDS) e 10,16m (CGIAR-CSI) mostram uma diferença aproximada de 10\%, para mais ou para menos, 
em relação aos valores encontrados por SANTOS et al. (2006) na Região Amazônica (faixa $02^{\circ} \mathrm{S}-02^{\circ} \mathrm{N}$ ), onde o desvio-padrão encontrado foi de $11,066 \mathrm{~m}$.

Para melhorar a interpretação dos resultados e possibilitar comparações com outros estudos, gerou-se o Quadro 6, indicando o Root-Mean-Square Error (RMSE), o erro mínimo e o erro máximo.

Registra-se que é inadequado afirmar que o modelo SRTM, seja ele de que fonte for, comporta-se sempre fornecendo altitudes maiores ou sempre menores do que as homólogas medidas em campo. Isso fica claro neste trabalho ao notarmos que os erros médios possuem valores positivos e negativos (Quadro 5, pontos da faixa de latitude $02^{\circ} \mathrm{N}-06^{\circ} \mathrm{N}$ ) e, em alguns casos, o erro médio pode ser positivo em um modelo e negativo em outro modelo para o mesmo conjunto de pontos (Quadro 5, pontos da faixa de latitude $\left.06^{\circ} \mathrm{S}-02^{\circ} \mathrm{S}\right)$.

Quadro 6- Resumo das acurácias Obtidas por Faixa de Latitudes.

\begin{tabular}{|c|c|c|c|c|c|c|c|c|c|}
\hline \multirow[t]{2}{*}{ Faixa } & \multirow{2}{*}{$\begin{array}{c}\text { Pontos medidos } \\
\text { em campo }\end{array}$} & \multicolumn{4}{|c|}{ Erro Mínimo--Erro Máximo (em módulo) } & \multicolumn{4}{|c|}{ RMSE } \\
\hline & & CGIAR-CSI & $\begin{array}{l}\text { SRTM } \\
\text { EMBRAPA }\end{array}$ & HỵdroSHEDS & $\begin{array}{l}\text { SRTM } \\
\text { Ferranti }\end{array}$ & CGIAR-CSI & $\begin{array}{l}\text { SRTM } \\
\text { EMBRAPA }\end{array}$ & HydroSHEDS & $\begin{array}{l}\text { SRTM } \\
\text { Ferranti }\end{array}$ \\
\hline $02^{\circ} \mathrm{N}-06^{\circ} \mathrm{N}$ & 76 & $0,06 \mathrm{~m}-15,27 \mathrm{~m}$ & $0,05 \mathrm{~m}-16,45 \mathrm{~m}$ & $0,289 \mathrm{~m}-34,66 \mathrm{~m}$ & $0,04 \mathrm{~m}-14,81 \mathrm{~m}$ & $4,35 \mathrm{~m}$ & $5,42 \mathrm{~m}$ & $14,11 \mathrm{~m}$ & $3,82 \mathrm{~m}$ \\
\hline $02^{\circ} \mathrm{S}-02^{\circ} \mathrm{N}$ & 159 & $0,28 \mathrm{~m}-43,62$ & $1,16 \mathrm{~m}-44,51 \mathrm{~m}$ & $0,11 \mathrm{~m}-32,64 \mathrm{~m}$ & $0,41 \mathrm{~m}-32,77 \mathrm{~m}$ & $16,62 \mathrm{~m}$ & 17,94 & $12,68 \mathrm{~m}$ & 14,69 \\
\hline $06^{\circ} \mathrm{S}-02^{\circ} \mathrm{S}$ & 51 & $0,11 \mathrm{~m}-12,02 \mathrm{~m}$ & $0,30 \mathrm{~m}-35,57 \mathrm{~m}$ & $0,20 \mathrm{~m}-34,33 \mathrm{~m}$ & $0,21 \mathrm{~m}-9,89 \mathrm{~m}$ & $5,57 \mathrm{~m}$ & $9,89 \mathrm{~m}$ & $17,01 \mathrm{~m}$ & $4,90 \mathrm{~m}$ \\
\hline $10^{\circ} \mathrm{S}-06^{\circ} \mathrm{S}$ & 134 & $0,02 \mathrm{~m}-22,47 \mathrm{~m}$ & $0,02 \mathrm{~m}-42,64 \mathrm{~mm}$ & $0,16 \mathrm{~m}-37,68 \mathrm{~m}$ & $0,04 \mathrm{~m}-18,84 \mathrm{~m}$ & $6,80 \mathrm{~m}$ & $9,13 \mathrm{~m}$ & $10,42 \mathrm{~m}$ & $5,36 \mathrm{~m}$ \\
\hline $14^{\circ} \mathrm{S}-10^{\circ} \mathrm{S}$ & 132 & $0,82 \mathrm{~m}-54,75 \mathrm{~m}$ & $0,15 \mathrm{~m}-71,30 \mathrm{~m}$ & $0,18 \mathrm{~m}--49,02 \mathrm{~m}$ & $0,22 \mathrm{~m}-23,71 \mathrm{~m}$ & $18,43 \mathrm{~m}$ & $17,53 \mathrm{~m}$ & $15,60 \mathrm{~m}$ & $9,61 \mathrm{~m}$ \\
\hline $18^{\circ} \mathrm{S}-14^{\circ} \mathrm{S}$ & 149 & $0,06 \mathrm{~m}-26,02 \mathrm{~m}$ & $0,48 \mathrm{~m}-26,57 \mathrm{~m}$ & $0,12 \mathrm{~m}-25,28 \mathrm{~m}$ & $0,01 \mathrm{~m}-20,74 \mathrm{~m}$ & 10,13 & $11,58 \mathrm{~m}$ & $8,83 \mathrm{~m}$ & $9,21 \mathrm{~m}$ \\
\hline $22^{\circ} \mathrm{S}-18^{\circ} \mathrm{S}$ & 69 & $0,02 \mathrm{~m}-13,23 \mathrm{~m}$ & $0,95 \mathrm{~m}-19,69 \mathrm{~m}$ & $0,33 \mathrm{~m}-15,66 \mathrm{~m}$ & $2,17 \mathrm{~m}-15,47 \mathrm{~m}$ & $7,46 \mathrm{~m}$ & $9,84 \mathrm{~m}$ & $7,23 \mathrm{~m}$ & $7,55 \mathrm{~m}$ \\
\hline $26^{\circ} \mathrm{S}-22^{\circ} \mathrm{S}$ & 127 & $1,10 \mathrm{~m}-39,79 \mathrm{~m}$ & $0,13 \mathrm{~m}-54,43 \mathrm{~m}$ & $0,16 \mathrm{~m}-34,16 \mathrm{~m}$ & $0,59 \mathrm{~m}-24,52 \mathrm{~m}$ & $15,49 \mathrm{~m}$ & $17,08 \mathrm{~m}$ & $11,45 \mathrm{~m}$ & $10,78 \mathrm{~m}$ \\
\hline $30^{\circ} \mathrm{S}-26^{\circ} \mathrm{S}$ & 190 & $0,08 \mathrm{~m}-49,25 \mathrm{~m}$ & $0,06 \mathrm{~m}-76,98 \mathrm{~m}$ & $0,03 \mathrm{~m}-63,68 \mathrm{~m}$ & $0,02 \mathrm{~m}-36,64 \mathrm{~m}$ & $12,31 \mathrm{~m}$ & $16,16 \mathrm{~m}$ & $14,74 \mathrm{~m}$ & $9,27 \mathrm{~m}$ \\
\hline Total (BRASIL) & 1087 & $0,02 \mathrm{~m}-54,75 \mathrm{~m}$ & $0,02 \mathrm{~m}-76,98 \mathrm{~m}$ & $0,03 \mathrm{~m}--63,68 \mathrm{~m}$ & $0,01 \mathrm{~m}-36,64 \mathrm{~m}$ & $12,74 \mathrm{~m}$ & $14,34 \mathrm{~m}$ & $12,70 \mathrm{~m}$ & $9,61 \mathrm{~m}$ \\
\hline
\end{tabular}

\subsection{Classificação do PEC}

Para a classificação quanto ao PEC, foram feitas duas análises: uma local, por faixas de Latitude; e outra geral, para todo o Brasil, conforme quadro 7. 
Dessa forma, ao considerar todos os modelos na escala 1:100.000, temos alguns com PEC "B" em algumas faixas de latitude, mas todos os modelos são classificados, no conjunto "Brasil”, como PEC “A”.

Para a escala 1:50.000, algumas faixas possuem classificação “A”, "B” ou "C" quanto ao PEC, mas no conjunto "Brasill", nenhum modelo foi passível de classificação (quadro 7). Contudo, o modelo que mais se aproximou de uma classificação no conjunto total de pontos foi o modelo de Jhonatan de Ferranti, no qual o limite para os erros de $90 \%$ dos pontos seria de $15,0 \mathrm{~m}$, mas o resultado indicou 15,52m para esse parâmetro, impedindo seu enquadramento como PEC “C C" na escala 1:50.000.

Assim, no que concerne ao PEC, o Modelo SRTM disponibilizado por Jhonatan de Ferranti apresenta resultados consideravelmente melhores, com menores erros para "90\% dos pontos" e desvio-Padrão (Quadro 5). Os modelos HydroSHEDS e CGIAR-CSI demonstram desempenho análogo e são mais uniformes e precisos do que o modelo da EMBRAPA. O modelo da EMBRAPA é o que mais oscila dentro da classificação do PEC, ou seja, das 9 faixas analisadas, há 4 classificadas como PEC “B” e 5, como PEC “A”, na escala 1:100.000.

Quadro 7- Classificação quanto ao PEC por faixa de Latitude.

\begin{tabular}{|c|c|c|c|c|c|c|c|c|c|c|c|c|}
\hline \multirow[t]{2}{*}{ Faixa } & \multicolumn{4}{|c|}{$\mathbf{9 0 \%}$ dos pontos $<$} & \multicolumn{4}{|c|}{ PEC-1:100.000 } & \multicolumn{4}{|c|}{ PEC-1:50.000 } \\
\hline & $\begin{array}{l}\text { CGIAR- } \\
\text { CSI }\end{array}$ & \begin{tabular}{|l|} 
SRTM \\
EM BRAPA
\end{tabular} & $\begin{array}{c}\text { HydroSHE } \\
\text { DS }\end{array}$ & $\begin{array}{l}\text { SRTM } \\
\text { Ferranti }\end{array}$ & CGIAR-CSI & \begin{tabular}{|l|} 
SRTM \\
EM BRAPA
\end{tabular} & HydroSHEDS & \begin{tabular}{|l|} 
SRTM \\
Ferranti
\end{tabular} & CGIAR-CSI & \begin{tabular}{|l} 
SRTM \\
EMBRAPA
\end{tabular} & $\begin{array}{l}\text { HydroSHED } \\
\text { S }\end{array}$ & \begin{tabular}{|l} 
SRTM \\
Ferranti
\end{tabular} \\
\hline $02^{\circ} \mathrm{N}-06^{\circ} \mathrm{N}$ & $5,81 \mathrm{~m}$ & $9,74 \mathrm{~m}$ & $21,65 \mathrm{~m}$ & $5,29 m$ & A & A & A & A & A & A & $X$ & A \\
\hline $02^{\circ} \mathrm{S}-02^{\circ} \mathrm{N}$ & $24,38 m$ & $27,16 \mathrm{~m}$ & $18,5 \mathrm{~m}$ & $21,44 \mathrm{~m}$ & $\mathrm{~A}$ & B & A & A & $X$ & $\mathrm{X}$ & $X$ & $X$ \\
\hline $06^{\circ} \mathrm{S}-02^{\circ} \mathrm{S}$ & $7,99 \mathrm{~m}$ & $11,1 \mathrm{~m}$ & $23,3 \mathrm{~m}$ & $7,52 \mathrm{~m}$ & $\mathrm{~A}$ & A & B & A & $\mathrm{A}$ & $\mathrm{C}$ & $X$ & $\mathrm{~A}$ \\
\hline $10^{\circ} \mathrm{S}-06^{\circ} \mathrm{S}$ & $12,52 \mathrm{~m}$ & $13,84 \mathrm{~m}$ & $16,59 \mathrm{~m}$ & $9,26 \mathrm{~m}$ & $\mathrm{~A}$ & $\mathrm{~A}$ & A & A & $\mathrm{C}$ & $\mathrm{C}$ & $X$ & $\mathrm{~A}$ \\
\hline $14^{\circ} \mathrm{S}-10^{\circ} \mathrm{S}$ & $29,01 \mathrm{~m}$ & $26,19 m$ & $24,26 \mathrm{~m}$ & $14,13 m$ & B & B & A & A & $\mathrm{X}$ & $\mathrm{X}$ & $X$ & C \\
\hline $18^{\circ} \mathrm{S}-14^{\circ} \mathrm{S}$ & $15,77 \mathrm{~m}$ & $19,07 \mathrm{~m}$ & $13,12 \mathrm{~m}$ & $14,33 m$ & A & A & A & A & $\mathrm{X}$ & $\mathrm{X}$ & $\mathrm{C}$ & C \\
\hline $22^{\circ} \mathrm{S}-18^{\circ} \mathrm{S}$ & $10,47 \mathrm{~m}$ & $14,43 \mathrm{~m}$ & $9,86 \mathrm{~m}$ & $10,83 m$ & A & A & A & A & B & $\mathrm{C}$ & B & B \\
\hline $26^{\circ} \mathrm{S}-22^{\circ} \mathrm{S}$ & $23,78 \mathrm{~m}$ & $26,85 \mathrm{~m}$ & $16,66 \mathrm{~m}$ & $15,8 \mathrm{~m}$ & A & B & A & A & $\mathrm{X}$ & $\mathrm{X}$ & $X$ & $\mathrm{X}$ \\
\hline $30^{\circ} \mathrm{S}-26^{\circ} \mathrm{S}$ & $17,59 \mathrm{~m}$ & $25,68 \mathrm{~m}$ & $23,94 \mathrm{~m}$ & $15,4 \mathrm{~m}$ & A & B & A & A & $\mathrm{X}$ & $\mathrm{X}$ & X & $\mathrm{X}$ \\
\hline Total (BRASIL) & $19,71 \mathrm{~m}$ & $22,55 \mathrm{~m}$ & $20,36 \mathrm{~m}$ & $15,52 \mathrm{~m}$ & $\mathbf{A}$ & A & A & A & $\mathbf{X}$ & $\mathbf{X}$ & $\mathbf{X}$ & $\mathbf{X}$ \\
\hline
\end{tabular}


No que concerne ao PEC-PCD (quadro 4), a fim de aumentar o escopo possível das comparações entre os resultados aqui obtidos e demais estudos correlatos, segue uma classificação nos termos do novo PEC-PCD (quadro 8), conforme legislação cartográfica nacional vigente.

Quadro 8- Classificação quanto ao PEC-PCD por faixa de Latitude.

\begin{tabular}{|c|c|c|c|c|c|c|c|c|c|c|c|c|}
\hline \multirow[t]{2}{*}{ Faixa } & \multicolumn{4}{|c|}{$90 \%$ dos pontos $<$} & \multicolumn{4}{|c|}{ PEC-PCD-1:100.000 } & \multicolumn{4}{|c|}{ PEC-PCD-1:50.000 } \\
\hline & $\begin{array}{l}\text { CGIAR- } \\
\text { CSI }\end{array}$ & $\begin{array}{l}\text { SRTM } \\
\text { EMBRAPA }\end{array}$ & HydroSHEDS & $\begin{array}{l}\text { SRTM } \\
\text { Ferranti }\end{array}$ & $\begin{array}{l}\text { CGIAR- } \\
\text { CSI }\end{array}$ & \begin{tabular}{|l|} 
SRTM \\
EMBRAPA
\end{tabular} & HydroSHEDS & \begin{tabular}{|l} 
SRTM \\
Ferranti
\end{tabular} & $\begin{array}{l}\text { CGIAR- } \\
\text { CSI }\end{array}$ & $\begin{array}{l}\text { SRTM } \\
\text { EMBRAPA }\end{array}$ & HydroSHEDS & $\begin{array}{l}\text { SRTM } \\
\text { Ferranti }\end{array}$ \\
\hline $02^{\circ} \mathrm{N}-06^{\circ} \mathrm{N}$ & $5,81 \mathrm{~m}$ & $9,74 \mathrm{~m}$ & $21,65 \mathrm{~m}$ & $5,29 \mathrm{~m}$ & A & B & B & A & B & B & $\mathrm{X}$ & B \\
\hline $02^{\circ} \mathrm{S}-02^{\circ} \mathrm{N}$ & $24,38 \mathrm{~m}$ & $27,16 \mathrm{~m}$ & $18,5 \mathrm{~m}$ & $21,44 \mathrm{~m}$ & B & $\mathrm{C}$ & B & B & $\mathrm{x}$ & $\mathrm{X}$ & $\mathrm{X}$ & $\mathrm{X}$ \\
\hline $06^{\circ} \mathrm{S}-02^{\circ} \mathrm{S}$ & $7,99 \mathrm{~m}$ & $11,1 \mathrm{~m}$ & $23,3 \mathrm{~m}$ & $7,52 \mathrm{~m}$ & $\mathrm{~A}$ & $B$ & $\mathrm{C}$ & A & $B$ & $\mathrm{D}$ & $\mathrm{X}$ & $B$ \\
\hline $10^{\circ} \mathrm{S}-06^{\circ} \mathrm{S}$ & $12,52 \mathrm{~m}$ & $13,84 \mathrm{~m}$ & $16,59 \mathrm{~m}$ & $9,26 \mathrm{~m}$ & $\mathrm{~A}$ & $B$ & $B$ & $\mathrm{~A}$ & $\mathrm{D}$ & $\mathrm{D}$ & $\mathrm{X}$ & $B$ \\
\hline $14^{\circ} \mathrm{S}-10^{\circ} \mathrm{S}$ & $29,01 \mathrm{~m}$ & $26,19 \mathrm{~m}$ & $24,26 \mathrm{~m}$ & $14,13 \mathrm{~m}$ & $\mathrm{C}$ & $\mathrm{C}$ & B & $B$ & $\mathrm{X}$ & $\mathrm{X}$ & $\mathrm{X}$ & $\mathrm{D}$ \\
\hline $18^{\circ} \mathrm{S}-14^{\circ} \mathrm{S}$ & $15,77 \mathrm{~m}$ & $19,07 \mathrm{~m}$ & $13,12 \mathrm{~m}$ & $14,33 \mathrm{~m}$ & $\mathrm{C}$ & $B$ & $B$ & $B$ & $\mathrm{X}$ & $\mathrm{X}$ & $\mathrm{D}$ & $\mathrm{D}$ \\
\hline $22^{\circ} \mathrm{S}-18^{\circ} \mathrm{S}$ & $10,47 \mathrm{~m}$ & $14,43 \mathrm{~m}$ & $9,86 \mathrm{~m}$ & $10,83 \mathrm{~m}$ & $\mathrm{~A}$ & B & $\mathrm{A}$ & $\mathrm{A}$ & $\mathrm{C}$ & $\mathrm{D}$ & $\mathrm{C}$ & $\mathrm{C}$ \\
\hline $26^{\circ} \mathrm{S}-22^{\circ} \mathrm{S}$ & $23,78 \mathrm{~m}$ & $26,85 \mathrm{~m}$ & $16,66 \mathrm{~m}$ & $15,8 \mathrm{~m}$ & $B$ & $\mathrm{C}$ & $B$ & $B$ & $\mathrm{X}$ & $X$ & $\mathrm{X}$ & $\mathrm{X}$ \\
\hline $30^{\circ} \mathrm{S}-26^{\circ} \mathrm{S}$ & $17,59 \mathrm{~m}$ & $25,68 \mathrm{~m}$ & $23,94 \mathrm{~m}$ & $15,4 \mathrm{~m}$ & $B$ & $\mathrm{C}$ & $\mathrm{B}$ & B & $\mathrm{X}$ & $\mathrm{X}$ & $\mathrm{X}$ & $\mathrm{X}$ \\
\hline Total (BRASIL) & $19,7 \mathrm{~lm}$ & $22,55 \mathrm{~m}$ & $20,36 \mathrm{~m}$ & $15,52 \mathrm{~m}$ & B & B & B & B & $\mathrm{X}$ & $\mathrm{X}$ & $\mathrm{x}$ & $\mathrm{X}$ \\
\hline
\end{tabular}

Acrescente-se que, na leitura desse estudo, a maioria das considerações são relativas ao PEC, e não ao PEC-PCD. Assim, a fim de evitar equívocos, o interessado deve estar atento a esse detalhe.

4.3 Análise da influência da Declividade na Acurácia Altimétrica O erro altimétrico varia de acordo com a declividade em dados SRTM (GOROKHOVICH \& VOUSTIANIOUK, 2006). Normalmente percebe-se um aumento do erro médio e do desvio-padrão à medida que aumenta a declividade da região, ou seja, em uma região montanhosa há de se esperar erros maiores do que em regiões de topografia mais suave (REXER \& HIRT, 2014). Para esta análise, foram utilizados os valores altimétricos do modelo SRTM produzido por Jonathan de Ferranti, por apresentarem melhor acurácia. Para a determinação dos erros foram utilizados os valores absolutos, apesar de a análise com os valores relativos, ou seja, considerando erros positivos e negativos, não alterarem os resultados. O erro médio 
varia aproximadamente de forma linear com as faixas de declividade (em \%), semelhante ao indicado por SHORTRIDGE \& MESSINA (2011).

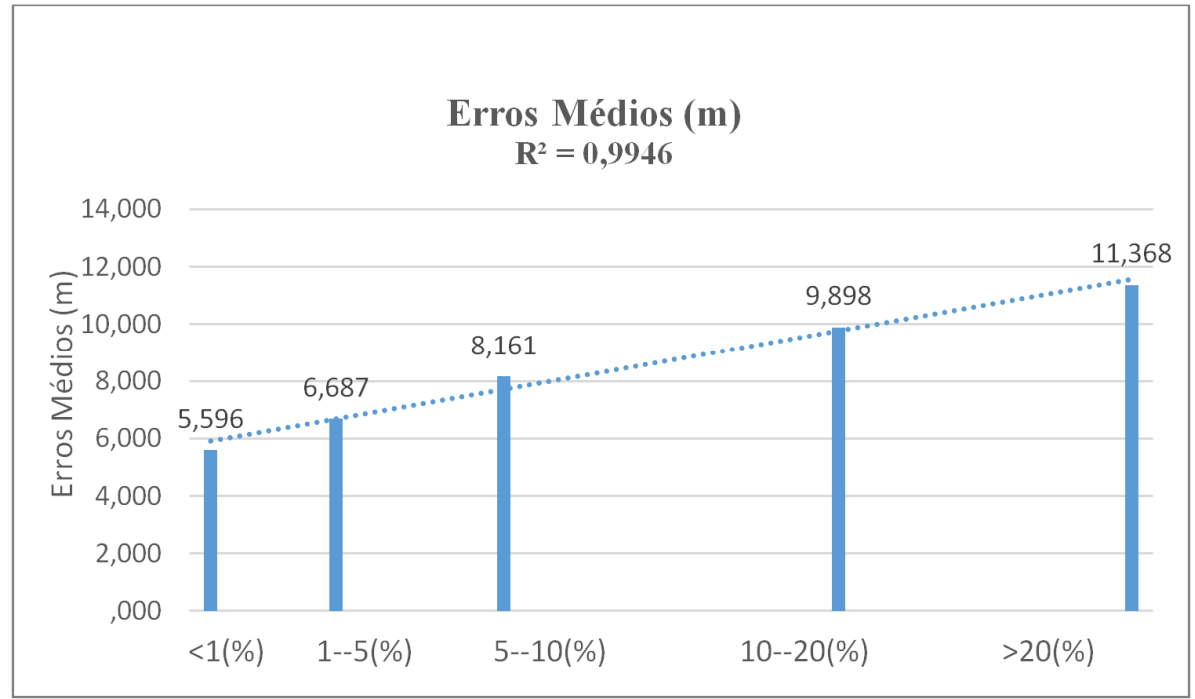

Figura 6- Erro médio em função da declividade (\%). $\mathrm{R}^{2}$ : coeficiente de

Determinação.

O Desvio-Padrão dos erros também possui comportamento semelhante ao apresentado pela média dos erros, ou seja, aumenta de forma aproximadamente linear com o aumento da declividade, como se observa na figura 7.

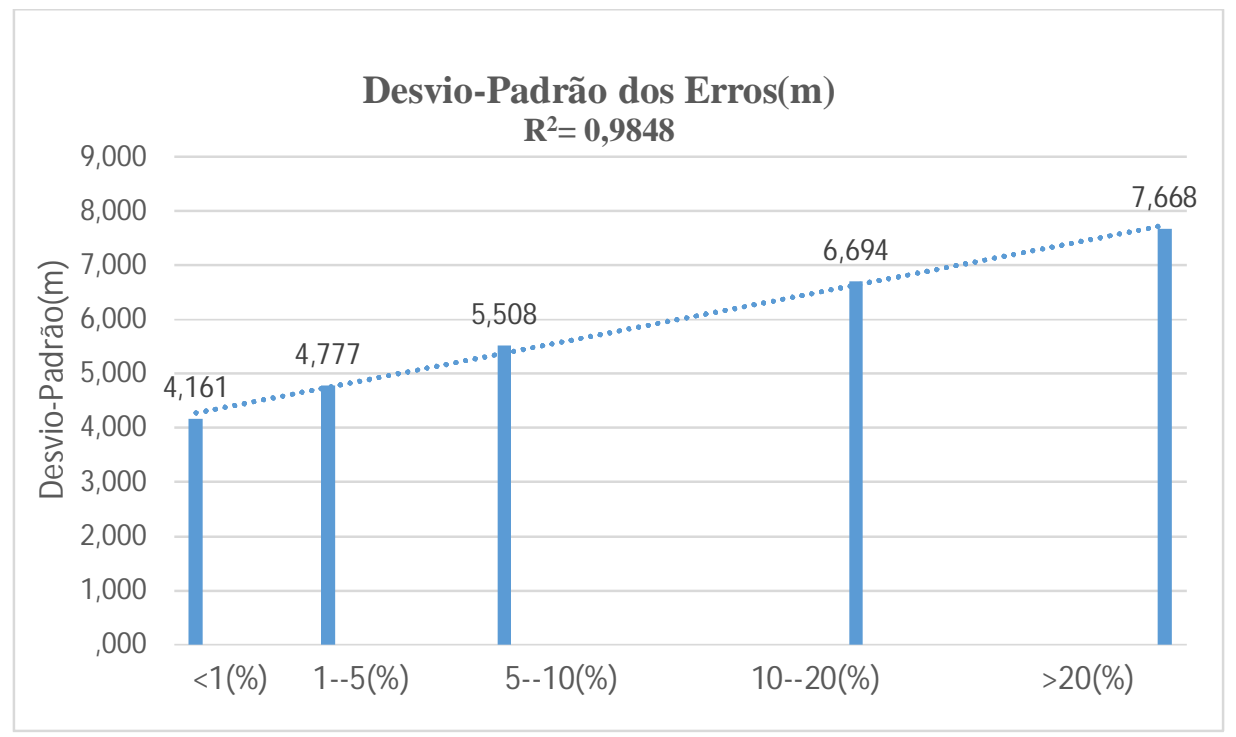

Figura 7- Desvio-Padrão dos erros em função da declividade (\%). $\mathrm{R}^{2}$ : coeficiente de Determinação. 
A média dos erros e o desvio padrão também foram determinados retirando-se da base de dados os 100 maiores erros (outliers) para verificar o comportamento do coeficiente de correlação. Entretanto, a figura 8 mostra que a média dos erros se mantém de forma linear.

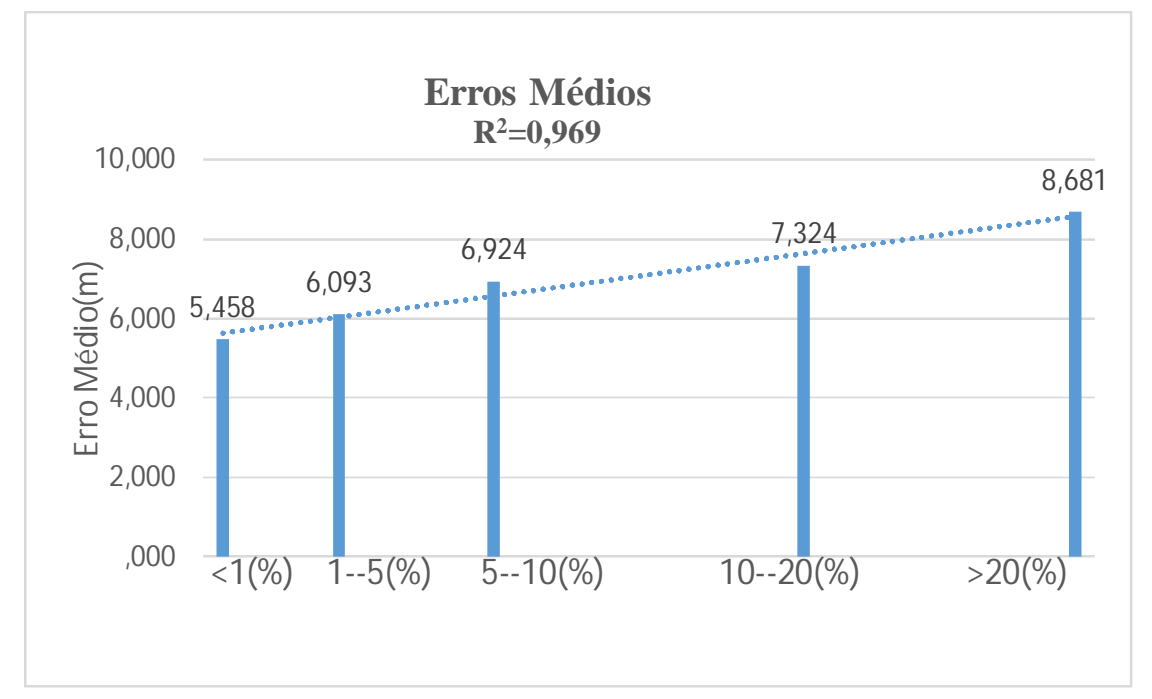

Figura 8- gráfico do erro médio em função da declividade (\%), excluídos os 100 maiores erros. $\mathrm{R}^{2}$ : coeficiente de Determinação.

4.4 Análise da influência da Vegetação na Acurácia Altimétrica O Modelo fornecido por Jhonatan de Ferranti foi tomado como referência para esta análise, uma vez que se mostrou o mais acurado dentre os modelos avaliados neste estudo. Ao analisar todos os maiores erros dentro de cada faixa de Latitude avaliada (Quadro 6), constata-se que eles ocorrem em áreas com densa vegetação, conforme a figura 9. Ainda que não tenha sido feita uma avaliação quantitativa da altura da vegetação, mas, simplesmente, posicional, a simples análise qualitativa indica a influência da vegetação na acurácia dos Modelos SRTM. 
Maiores Erros (m) para o Modelo de Jhonatan Ferranti no Brasil
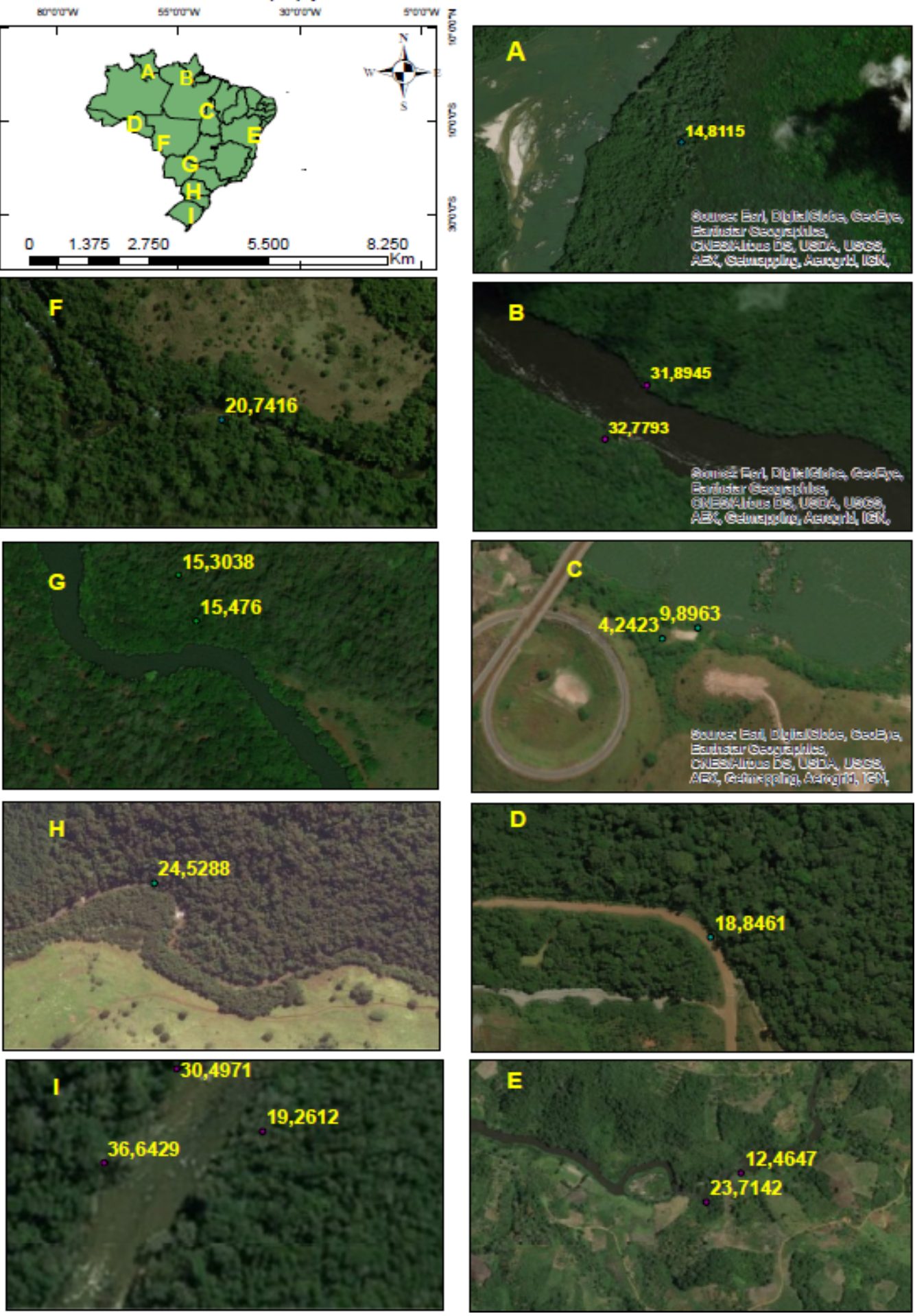

Figura 9- análise dos maiores erros por faixa de latitude e sua incidência em regiões com vegetação.

Fonte das Imagens: Esri, DigitalGlobe, GeoEye, Earthstar Geographicas, CNES/Airbus DS, USDA, USGS, AEX, Getmapping, Aerogrid, IGN, IGP, swisstopo, the GISUser Community. 
Portanto, fica nítida a influência da vegetação na acurácia dos Modelos SRTM, principalmente ao verificar a acurácia obtida na componente altimétrica das coordenadas de um ponto. Confirmando o que afirmou SHORTRIDGE \& MESSINA (2011) sobre a importância de se avaliar separadamente os maiores erros encontrados. Além disso, os resultados aqui mostrados convergem com as suas conclusões para a influência da vegetação na acurácia altimétrica do SRTM.

\section{Discussão}

\subsection{Acurácia altimétrica dos Modelos SRTM}

Ao comparar os resultados aqui mostrados com estudos globais, o quadro 5 mostra um erro médio que varia de $8,96 \mathrm{~m}$ até $0,24 \mathrm{~m}$ e desvio-padrão de $12,70 \mathrm{~m}$ até 7,22m, que diverge dos resultados apresentados por BERRY, et al., (2007), onde o erro médio é de $12,22 \mathrm{~m}$ e o desvio-padrão de $18,51 \mathrm{~m}$ para a América do Sul. Considerando que o Brasil representa quase metade do território da América do Sul, os modelos SRTM podem possuir acurácia altimétrica superior ao mostrado por BERRY, et al., (2007) nessa região. Isso já foi mostrado por MUKUL et al., (2015) também em uma análise global, onde se observa um erro médio de 5,2m com desviopadrão de 10,2m, resultado próximo ao obtido no modelo SRTM disponibilizado por Jhonatan de Ferranti com erro médio de 6,33m e desvio-padrão de 7,22m (Quadro 9). Além disso, é importante destacar que BERRY et al., (2007) utiliza altimetria obtida por satélite (grande massa de pontos em todos os continentes), enquanto MUKUL et al., (2015) faz a comparação com pontos de campo (Ground Control Points-GCPs). Dessa forma, os procedimentos que mais se assemelham com este estudo são aqueles executados por MUKUL et al., (2015), assim como os resultados obtidos. 
Quadro 9- Resultados de estudos globais e deste estudo.

\begin{tabular}{|c|c|c|}
\hline Referência & Local & Resultados \\
\hline BERRY et al (2007). & América do Sul & Erro médio: 12,22m; Desvio-Padrão: 18,51m. \\
\hline $\begin{array}{c}\text { MUKUL et al } \\
(2015)\end{array}$ & América do Sul & Erro médio: 5,2m; Desvio-Padrão:10,2m. \\
\hline Este Estudo & Brasil & Erro médio: 6,33m; Desvio-Padrão: 7,22m. \\
\hline
\end{tabular}

Os resultados mostram que há diferenças significativas entre os diversos modelos SRTM, sendo o modelo fornecido por Jhonatan de Ferranti aquele que apresenta o comportamento mais constante e com melhor desempenho do que os outros modelos SRTM na avaliação de sua acurácia altimétrica (altitude ortométrica).

Em segundo plano, o Modelo fornecido pelo CGIAR-CSI (Consultative Group for International Agricultural Research-Consortium for Spatial Information) demonstra bons resultados, e pode ser enquadrado como o segundo melhor modelo nas avaliações em território brasileiro.

\subsection{Relação entre Declividade e Acurácia altimétrica}

Outro fator evidenciado e bastante relevante no uso desses modelos é que sua acurácia está diretamente ligada à faixa de declividade do terreno em estudo, uma vez que o erro médio aumenta com a elevação da declividade (Figura 6 e Figura 7), como também se observa em KARWEL \& EWIAK (2008) na Polônia, em MUKHERJEE et al. (2013) na região do Himalaia.

Assim, uma consideração relevante é a separação das regiões estudadas em tipos de relevo conforme a sua declividade. Tal consideração foi realizada por KARWEL \& EWIAK (2008), onde evidenciou que o terreno plano apresenta um valor de RMSE (2,9m) quase metade do valor do RMSE para um terreno montanhoso $(5,4 \mathrm{~m})$ (quadro1).

Ainda no que concerne à influência da declividade na magnitude dos erros, é razoável afirmar que a declividade afeta diretamente a acurácia do MDE, uma vez 
que em regiões mais movimentadas há maior incidência de áreas com "sombras", ou seja, regiões com vazios de dados. Nesses locais, os dados apresentados são resultados de interpolações, fazendo com que os erros sejam maiores em regiões com maior declividade. Assim, torna-se imperativo que em paralelo com o uso do Modelo SRTM, seja avaliada a declividade da região, pois em regiões mais movimentadas, ocorrerão maiores erros.

\subsection{Influência da Vegetação na Acurácia Altimétrica}

Foi observado que a vegetação influencia a acurácia dos modelos, fato evidenciado ao se constatar que todos os maiores erros estavam em região com vegetação. Assim, conclui-se que há diferenças na acurácia altimétrica esperada não somente em virtude da declividade, mas também pelo tipo de cobertura vegetal, tanto a altura das árvores quanto a sua densidade, ou de uma forma mais geral, em função do Bioma que contém a área em estudo. SHORTRIDGE \& MESSINA (2011) e LIU (2008) mostram, em seus estudos, que as regiões com maior porcentagem de cobertura vegetal concentram os maiores erros altimétricos das avaliações realizadas no modelo SRTM. Além da porcentagem de cobertura vegetal, a altura das árvores também influenciará na acurácia dos resultados, já que a onda utilizada para gerar o Modelo Digital de Elevação do SRTM é espalhada pela superfície da copa da vegetação, sendo esta a superfície representada pelo SRTM.

Assim, espera-se que, em regiões de florestas tropicais, o SRTM possua acurácia inferior a regiões de menor densidade de cobertura vegetal, como indica SHORTRIDGE \& MESSINA (2011).

\section{Conclusão}

Os resultados demonstraram que a acurácia vertical do Modelo fornecido pelo SRTM varia ao longo do território brasileiro, apresentando para os 1087 pontos 
distribuídos no Brasil: erro médio de 8,96m e desvio-padrão de 11,20m para os modelos da EMBRAPA; erro médio de 0,24m e desvio-padrão de $12,70 \mathrm{~m}$ para o HydroSHEDS; erro médio de 9,78m e desvio-padrão de 8,16m para CGIAR-CSI; erro médio de 6,33m e desvio-padrão de 7,22m para Jhonatan de Ferranti. Além disso, no conjunto dos 1087 pontos, todos os Modelos podem ser classificados no Padrão de Exatidão Cartográfica como "A” para a escala de 1:100.000, mas podem apresentar resultados melhores em termos locais. Assim, a origem do modelo utilizado já é fator que gera implicações nas precisões dos produtos gerados, pois 4 modelos com a mesma resolução espacial (90metros) apresentam resultados muito diferentes.

Além disso, mostraram-se determinantes na qualidade dos resultados o tipo de cobertura do solo e a declividade do terreno, impactando diretamente na acurácia dos produtos derivados de modelos SRTM. Tais conclusões, reforçadas pelas informações dos artigos pesquisados do quadro 1 , ratificam a ideia de que o usuário deve ter a exata noção da acurácia esperada do Modelo na região que será utilizado, além de sua compatibilidade com a escala desejada para a aplicação.

Além disso, a acurácia esperada varia também em função da fonte do Modelo, apesar de possuir a mesma resolução espacial. O modelo produzido por Jonathan de Ferranti, apesar de ter sido elaborado para preenchimento dos vazios em regiões montanhosas, apresentou os melhores resultados tanto em relevos planos quanto em movimentados.

Assim, todos esses fatores são importantes, mas não diminuem o valor agregado por esses Modelos obtidos de forma gratuita para muitos estudos que sejam compatíveis com a escala indicada. 


\section{Agradecimentos}

Gostaria de agradecer à Agência Nacional de Energia Elétrica (ANEEL) por possibilitar o desenvolvimento deste estudo colaborando não somente com os dados, mas também com todo o incentivo para a conclusão deste trabalho, particularmente à Superintendência de Gestão Técnica da Informação (SGI) e à equipe de Geoprocessamento da Agência.

\section{Sugestão para Trabalhos Futuros}

Ressalta-se que não houve um aprofundamento das características dos biomas estudados para relacionar outros dados mais técnicos sobre a influência da vegetação nas precisões dos modelos, como altura média das árvores e sua densidade por exemplo, sendo tal aprofundamento uma limitação deste estudo e uma sugestão para trabalhos futuros.

Além disso, o quadro 1 indica, em sua revisão bibliográfica, várias fontes utilizadas para avaliar o modelo SRTM, sendo possível um estudo mais detalhado para verificar o quanto a fonte utilizada impacta nos resultados finais da avaliação.

\section{Conclusão Geral}

Os resultados demonstram que são vários os fatores que afetam a acurácia dos Modelos do SRTM que são disponibilizados gratuitamente por fontes governamentais ou particulares.

A própria fonte de obtenção do Modelo SRTM deve ser levada em consideração, haja vista que as precisões variam em função dos processamentos executados por cada fonte que disponibiliza o SRTM. Neste estudo, as quatro fontes analisadas mostram resultados diferentes. Além da própria fonte, fatores como 
declividade e vegetação também são fundamentais para as precisões que serão obtidas e impactam diretamente nos usos possíveis para o Modelo.

Dessa forma, pelo esforço verificado em determinar as precisões dos Modelos do SRTM em todo o Mundo (quadro 1), nota-se a sua importância e o quanto o conhecimento de suas qualidades e limitações são relevantes para diversas áreas do conhecimento.

Assim, espera-se que este trabalho tenha contribuído para elucidar tanto potencialidades quanto as ressalvas a serem feitas no uso desse Modelo Digital de Elevação, sobretudo no vasto território brasileiro.

\section{REFERÊNCIAS BIBLIOGRÀFICAS}

Agência Nacional de Energia Elétrica (ANEEL), DIRETRIZES PARA ELABORAÇÃO DE SERVIÇOS DE CARTOGRAFIA E TOPOGRAFIA, RELATIVOS A ESTUDOS E PROJETOS DE APROVEITAMENTOS HIDRELÉTRICOS. Disponível em: http://www2.aneel.gov.br/scq/Doc/Diretrizes Topografia.pdf. Acesso em dezembro de 2016

Agência Nacional de Energia Elétrica (ANEEL), Diretrizes de Cartografia Acesso à Informação. Disponível em: http://www.aneel.gov.br/biblioteca/inventario.cfm. Acesso em outubro 2015

AMARAL, S., COSTA, C. B., ARASATO, L. S., XIMENES, A. C., RENNÒ, C. D. AMBDATA: Variáveis ambientais para Modelos de Distribuição de Espécies (MDEs). Anais XVI Simpósio Brasileiro de Sensoriamento Remoto, Foz do Iguaçu, Brasil, INPE, 2013.

ATHMANIA, D., ACHOUR, H. External Validation of the ASTER GDEM2, GMTED2010 and CGIAR-CSI- SRTM v4.1 Free Access Digital Elevation Models (DEMs) in Tunisia and Algeria. Remote Sens., 6, 4600-4620, 2014.

AZIZIAN, A.; SHOKOOHI, A. Effects of data resolution and stream delineation threshold area on the results of a kinematic wave based GIUH model. Water SA Vol. $41 \mathrm{~N}^{\circ} .1$ January 2015.

BERRY, P. A. M.; GARLICK, J. D.; SMITH, R. G. Near-global validation of the SRTM DEM using satellite radar altimetry. Remote Sensing of Environment, 106, 17-27, 2007. 
BIAS, S. E.; RIBEIRO, C. J. R.; BAPTISTA, M. M. G.; BERNARDI, E. V. J. Avaliação da Exatidão do MDE Obtido por Meio do SRTM e Pela Carta do IBGE na Escala 1:100.000. Revista Brasileira de Cartografia, n.63/01, p.149-155, 2010.

BRASIL 1984. Decreto $n^{\circ} 89.817$ de 20 de Julho de 1984. Estabelece as instruções reguladoras das Normas Técnicas da Cartografia Nacional. Disponível em http://www.planalto.gov.br/ccivil_03/decreto/1980-1989/D89817.htm. Acessado em: Outubro de 2015.

BROCHADO, G.T. Atenuação do efeito do desflorestamento em dados SRTM por meio de deferentes técnicas de interpolação. 2015. 113p. (sid.inpe.br/mtcm21b/2015/02.06.18.12-TDI). Dissertação (Mestrado em Sensoriamento Remoto) Instituto de Pesquisas Espaciais, São José dos Campos, 2015. Disponível em http://urlib.net/8JMKD3MGP3W34P/3HT5JCL. Acessado em: agosto de 2016.

CÂMARA, G.; DAVIS, C.; MONTEIRO, A.M.V. (Ed.). Introdução à Ciência da Geoinformação. Disponível em: http://mtcm12.sid.inpe.br/col/sid.inpe.br/sergio/2004/04.22.07.43/doc/publicacao.pdf. Acesso em: dezembro de 2016.

CAMARGOS, L. A., SILVA, C. C., MORAES, M. F., PRUDENTE, C. N. Aplicação do Modelo Digital de Terreno (MDT) Advanced Elevation Series (AES) em parte do município de Formosa, GO. Anais do XVII Simpósio Brasileiro do Sensoriamento Remoto, João Pessoa-PB, Brasil. INPE, p. 4559-4566, 2015.

CELESTINO, V.S.; PHILIPHS, J.W. Avaliação Altimétrica SRTM e ASTER GDEM em Áreas de Relevos Diferenciados. Revista Brasileira de Cartografia, n.68/01, p.1542, 2016.

CHAIEB, A.; REBAI, N.; BOUAZIZ, S. Vertical Accuracy Assessment of SRTM Ver 4.1 and ASTER GDEM Ver 2 Using GPS Measurements in Central West of Tunisia. Journal of Geographic Information System, 8, 57-64, 2016.

COELHO FILHO, L. C. T., BRITO, J. L. N. S. Fotogrametria Digital. Editora da Universidade do Rio de Janeiro. Rio de Janeiro, Brasil: 2007.

Consultative Group for International Agricultural Research-Consortium for Spatial Information (CGIAR-CSI). Disponível em: http://www.cgiar-csi.org/data/srtm-90mdigital-elevation-database-v4-1. Acesso em junho 2016.

DASGUPTA, S., LAPLANTE, B., MURRAY, S., WHEELER, D. Exposure of developing countries to sea-level rise and storm surges. Climatic Change, 106, 567$579,2011$.

DATTA, P. S., KIRCHNER, H. S. Erosion Relevant Topographical Parameters Derived from Different DEMs-A Comparative Study from the Indian Lesser Himalayas. Remote Sens. 2, 1941-1961, 2010.

Diretoria de Serviço Geográfico (DSG). Especificação técnica para a aquisição de dados geoespaciais vetoriais (ET- ADGV). Ministério da Defesa, Exército Brasileiro, Departamento de Ciência e Tecnologia. Brasília - DF, 2a edição, 2011.

FERNANDES, M.; MENEZES, P. M. L. Avaliação de métodos de geração de MDE para a obtenção de observações em superfície real: um estudo de caso no maciço da Tijuca-RJ. Anais do XII Simpósio Brasileiro do Sensoriamento Remoto, Goiânia, Brasil. INPE, p. 2985-2992, 2005. 
FERRANTI, J. Digital Elevation Data. Disponível em http://www.viewfinderpanoramas.org/dem3.html. Acesso em Junho 2016.

FREY, H.; PAUL, F. On the suitability of the SRTM DEM and ASTER GDEM for the compilation of topographic parameters in glacier inventories. International Journal of Applied Earth Observation and Geoinformation, 18, p. 480-490, 2012.

Fundação Instituto Brasileiro de Geografia e Estatística (IBGE), Mapa Índice Digital. Disponível

ftp://geoftp.ibge.gov.br/cartas_e_mapas/mapa_indice_digital_4ed/leia_me_4ed.pdf.

Acesso em outubro 2016.

GOROKHOVICH, A.; VOUSTIANIOUK, A. Accuracy assessment of the processed SRTM-based elevation data by CGIAR using field data from USA and Thailand and its relation to the terrain characteristics. Remote Sensing of Environment, 104, 409415, 2006.

GROHMANN, C.H.; RICCOMINI, C.; STEINER, S.S. Aplicações dos Modelos de Elevação SRTM em Geomorfologia. Revista Geográfica Acadêmica, v.2 n.2 (viii.2008) 73-83.

GÒMEZ-GUTIÈRREZ, A., SCHNABEL, S., CONTADOR, F. L., MARÌN, R. G. Testing the quality of open-access DEMs and their derived attributes in Spain: SRTM, GDEM and PNOA DEM. Geomorphometry, 2011.

HIGA, T. L.; FILHO, P. C. A.; TORRES, G. T; SALLES, T. A. Avaliação da precisão vertical do modelo SRTM para a bacia do rio Paraguai, no Estado de Mato Grosso do Sul. Anais $1^{\circ}$ Simpósio de Geotecnologias no Pantanal, Campo Grande, Brasil. Embrapa Informática Agropecuária/INPE, p.834-840, 2006.

HOFFMANN, J., WALTER, D. How Complementary are SRTM-X and -C Band Digital Elevation Models? Photogrammetric Engineering \& Remote Sensing, 72, 261-268, 2006.

IORIO, M. M.; LASTORIA, G.; MIOTO, C. L.; AlBREZ, A.; FILHO, P. C. A. Avaliação de Modelos Digitais de Elevação Extraídos de Imagem ALOS/PRISM e Comparação com os Modelos Disponibilizados Gratuitamente na WEB. Geociências, v. 31, n. 4, p. 650-664, 2012.

JARIHANI, A. A.; CALLOW, J. N.; MCVICAR, T. R.; NIEL, T. G. V.; LARSEN, J. R. Satellite-derived Digital Elevation Model (DEM) selection, preparation and correction for hydrodynamic modelling in large, low-gradient and data-sparse catchments. Journal of Hydrology 524, 489-506, 2015.

KARWEL, A. K., EWIAK, I. Estimation of the Accuracy of the SRTM Terrain Modelo $n$ the Area of Poland. The International Archives of the Photogrammetry, Remote Sensing and Spatial Information Sciences. Vol. XXXVII. Part B7. Beijing, 2008.

KOLECKA, N., KOZAK, J. Assessment of the Accuracy of SRTM C- and X-Band High Mountain Elevation Data: a Case Study of the Polish Tatra Mountains. Pure and Applied Geophysics, 171, 897-912, 2014.

LEHNER, B., VERDIN, K., JARVIS, A. HydroSHEDS Technical Documentation. World Wildlife Fund US, Washington, DC, 2006. Disponível em http://hydrosheds.cr.usgs.gov.

LEHNER, B. Derivation of watershed boundaries for GRDC gauging stations based on the HydroSHEDS drainage network. Global Runoff Data Centre (GRDC). Technical Report 41, 2012. 
LIU, Y. An Evaluation on the Data Quality of SRTM DEM at the Alpine and Plateau Area, North-Western of China. The International Archives of the Photogrammetry, Remote Sensing and Spatial Information Sciences. Vol. XXXVII. Part B1. Beijing, 2008.

LUDWIG, R., SCHNEIDER, P. Validation of digital elevation models from SRTM XSAR for applications in hydrologic modeling. ISPRS Journal of Photogrammetry \& Remote Sensing 60, 339-358, 2006.

MANTELLI, R. L.; ROSSETTI, F. D.; ALBUQUERQUE, G. P.; VALERIANO, M. M. Applying SRTM digital elevation model to unravel Quaternary drainage in forested areas of Northeastern Amazonia. Computers \& Geosciences 35, p. 2331-2337, 2009.

MEDEIROS, C. L.; FERREIRA, C. N.; FERREIRA, G. L. Avaliação de Modelos Digitais de Elevação para Delimitação Automática de Bacias Hidrográficas. Revista Brasileira de Cartografia, n.61/02, p.137-151, 2009.

MELO, M. S. Avaliação de Potencial Hidroelétrico com aplicação de Sistema de Informações Geográficoas. 2013. 230p. Tese de Doutorado Instituto de GeociênciasUnB, Brasília, 2013.

MICELI, S. B.; DIAS, M. F.; SEABRA, M. F.; SANTOS, A. R. P.; FERNANDES, C. M. Avaliação Vertical de Modelos Digitais de Elevação (MDEs) em Diferentes Configurações Topográficas para Médias e Pequenas Escalas. Revista Brasileira de Cartografia, n.63/01, p.191-201, 2011.

Ministério do Meio Ambiente (MMA), Acesso à Informação. Disponível em: http://www.mma.gov.br/biomas. Acesso em outubro 2016.

MIRANDA, E. E. de; (Coord.). Brasil em Relevo. Campinas: Embrapa Monitoramento por Satélite, 2005. Disponível em:<http://www.relevobr.cnpm.embrapa.br>. Acesso em: 13 set. 2015.

MOURA, L. Z.; BIAS, E. S.; BRITES, R. Avaliação Avaliação da Acurácia Vertical de Modelos Digitiais de Elevação (MDES) nas bacias do Paranoá e São Bartolomeu. Revista Brasileira de Cartografia, n.66/01, p.1-14, 2014.

MOURATIDIS, A., BRIOLE, P., KATSAMBALOS, K. Avaliação SRTM 300 DEM (versions $1,2,3,4$ ) validation by means of extensive kinematic GPS measurements: a case study from North Greece. International Journal of Remote Sensing Vol. 31, No. 23, 6205-6222, 2010.

MUKHERJEE, S.; JOSHI, P. K.; MUKHERJEE, S.; GHOSH, A. GARC, R. D.; MUKHOPADHYAY. Evaluation of vertical accuracy of open source Digital Elevation Model (DEM). International Journal of Applied Earth Observation and Geoinformation 21, p. 205-217, 2013.

MUKUL, M.; SRIVASTAVA, V.; MUKUL, M. Analysis of the accuracy of Shuttle Radar Topography Mission (SRTM) height models using International Global Navigation Satellite System Service (IGS) Network. Journal of Earth System Science, 124, p.1343-135721, 2015.

NÓBREGA, A. A. R.; SANTOS, C.; CINTRA, P. J. Comparação Quantitativa e Qualitativa entre o Modelo Digital Gerado pelo SRTM e por Aerofotogrametria. Anais XII Simpósio Brasileiro de Sensoriamento Remoto, Goiânia, Brasil, INPE, p. 44374444, 2005.

OPENDEM. Disponível em http://www.opendem.info/technology.html\#1. Acesso em novembro de 2016. 
OUERGHI, S.; ELSHEIKH, R. F. A.; ACHOUR, H. ; BOUAZI, S. Evaluation and Validation of Recent Freely-Available ASTER-GDEM V.2, SRTM V.4.1 and the DEM Derived from Topographical Map over SW Grombalia (Test Area) in North East of Tunisia. Journal of Geographic Information System, 7, 266-279,2015.

Portal Brasil. Ministério do meio ambiente. Disponível em http://www.brasil.gov.br/meio-ambiente/2009/10/biomas-brasileiros. Acesso em novembro de 2016.

REXER, M., HIRT, C. Comparison of free high resolution digital elevation data sets (ASTER GDEM2, SRTM v2.1/v4.1) and validation against accurate heights from the Australian National Gravity Database. Australian Journal of Earth Sciences 61:2, 213-226, 2014.

ROBINSON, N., REGETZ, J., GURALNICK, R.P. EarthEnv-DEM90: A nearly-global, void-free, multi-scale smoothed, 90m digital elevation model from fused ASTER and SRTM data. ISPRS Journal of Photogrammetry and Remote Sensing 87, 57-67, 2014.

SANTOS, A. R. P.; GABOARDI, C.; OLIVEIRA, C. L. Avaliação da Precisão Vertical dos Modelos SRTM para a Amazônia. Revista Brasileira de Cartografia, n.58/01, p.101-107, 2006.

Serviço Florestal Brasileiro (SFB). Florestas do Brasil em Resumo, 2013. Disponível em http://www.florestal.gov.br/snif/images/Publicacoes/florestas_do_brasil_em_resumo_20 13_atualizado.pdf. Acesso em novembro de 2016.

SHORTRIDGE, A., MESSINA, J. Near-global validation of the SRTM DEM using satellite radar altimetry. Remote Sensing of Environment, 115, 1576-1587, 2011.

SIART, Christoph; BUBENZER, olaf; EITEL, Bernhard. Combining digital elevation data (SRTM/ASTER), high resolution satellite imagery (Quickbird) and GIS for geomorphological mapping: A multi-component case study on Mediterranean karst in Central Crete. Geomorphology, 112, 106-121, 2009.

SUWANDANA, E., KAWAMURA, K., SAKUNO, Y., KUSTIANTO, E., RAHARJO, B. Evaluation of ASTER GDEM2 in Comparison with GDEM1, SRTM DEM and Topographic-Map-Derived DEM Using Inundation Area Analysis and RTK-DGPS Data. Remote Sens. 4, 2419-2431, 2012.

TAIT, A. Some useful Digital Elevation Datasets. Cartographic Perspectives, 67, 6374, 2010.

TARQUINI, S.; VINCI, S., FAVALli, M., DOUMAZ, F., FORNACIAI, A., NANNIPIERI, L. Release ofa10-m-resolution DEM for the Italian territory: Comparison with global-coverage DEMs and anaglyph-mode exploratio nvia the web. Computers\&Geosciences, 38, 409-415, 2012.

TERRAINMAP. Disponível em http://www.terrainmap.com/rm49.html. Acesso em novembro de 2016.

U.S. Geological Survey (USGS), HydroSHEDS. Disponível em: http://hydrosheds.cr.usgs.gov/hydro.php. Acesso em maio 2016.

U.S. Geological Survey (USGS), Shuttle Radar Topography Mission. Disponível em: http://srtm.usgs.gov/mission.php. Acesso em outubro 2015.

VALERIANO, M. M. Topodata: guia para utilização de dados geomorfológicos locais. São José dos Campos: INPE, 2008. 
VTERRAIN. Disponível em http://vterrain.org/Elevation/SRTM/. Acesso em novembro de 2016.

WANG, W., YANG, X., YAO, T. Evaluation of ASTER GDEM and SRTM and their suitability in hydraulic modelling of a glacial lake outburst flood in southeast Tibets. HYDROLOGICAL PROCESSES, 26, 213-225 (2012). 